\title{
El Internacionalismo de Theodore Roosevelt: el excepcionalismo enérgico de su política exterior
}

\author{
Pedro Fco. Ramos Josa \\ Doctorando en Paz y Seguridad Internacional \\ en el Instituto Universitario General Gutiérrez Mellado \\ The Internationalism of Theodore Roosevelt: \\ the Strenuous Exceptionalism of his Foreign Policy
}

\begin{abstract}
RESUMEN:
el objetivo de este artículo es estudiar el legado político de Theodore Roosevelt bajo la perspectiva de su política exterior y demostrar así su vigencia en pleno siglo

XXI, tanto por su influencia en la evolución del pensamiento político estadounidense como por sus propias características. $T$.

Roosevelt fue el primer Presidente en abandonar el unilateralismo aislacionista en materia de política exterior, para colocar a Estados Unidos en la senda internacionalista que hoy le caracteriza, de ahí que sea imprescindible analizar su pensamiento político en lo relativo a la política exterior. El excepcionalismo enérgico fue la respuesta elaborada por $T$. Roosevelt para resolver la ecuación formulada por el ascenso de Estados Unidos a potencia mundial y su tradicional retraimiento a la hora de participar en los asuntos mundiales. A partir de entonces $y$ bajo su impulso, comenzó un debate que está lejos de resolverse sobre qué papel debe desempeñar Estados Unidos en la comunidad internacional y cómo debe desempeñarlo.
\end{abstract}

PALABRAS CLAVE:

Theodore Roosevelt, Woodrow Wilson, Internacionalismo conservador,
ABSTRACT:

the aim of this article is to study the polical legacy of Theodore Roosevelt under the perspective of his foreign policy and to show its relevance in the $X X I$ century, both for his influence in the evolution of the american political thought and for its own characteristics. $T$. Roosevelt was the first President who dropped out the isolationist unilateralism in the realm of foreign policy, in order to put America in the internationalist path, hence it is essential to analyze his political thought relating to foreign policy. The strenuous internationalism was the answer that $T$. Roosevelt devised to settle the equation formulated by the rise of the United States to a world power status and its traditional shyness to be an active player in foreign affaires. Since then, and under his impetus, a debate was started that is far from being resolved about which is the rol that America should play in the internacional community and how it should be performed.

KEY WORDS:

Theodore Roosevelt, Woodrow Wilson, Conservative Internationalism, Democratic 
Internacionalismo liberal democrático, aislacionismo, unilateralismo, Sociedad de Naciones, OTAN, ONU.
Liberal Internationalism, Isolationism, Unilateralism, League of Nations, NATO, UN.

\section{INTRODUCCIÓN}

Es probable que no exista figura tan arquetípica del espíritu estadounidense como la del $26^{\circ}$ Presidente de Estados Unidos, Theodore Roosevelt, cuya vida se encuentra salpicada de pasajes tan contradictorios como su propia personalidad. Nacido en Nueva York el 27 de octubre de 1858', en el seno de una de las familias más influyentes de la ciudad, pronto conocería Europa de primera mano al viajar por el viejo continente con frecuencia, aunque su frágil salud le causaría dificultades desde muy joven, obligándole a realizar ejercicio físico rutinario para vencer su asma. Tras iniciar sus estudios en Harvard, publicó su primer libro a los 19 años sobre ornitología, su primera gran pasión, hasta que se inició en política una vez finalizados sus estudios. A los 23 años se convirtió en el miembro más joven de la Asamblea estatal de Nueva York, al mismo tiempo que publicaba su visión sobre la guerra con Gran Bretaña de 1812, The Naval War of 1812, convertida en obra de referencia sobre el conflicto y en un alegato directo a favor de la modernización de la Marina estadounidense. A partir de entonces su vida se aceleraría de tal manera que cuando alcanzó la Presidencia, T. Roosevelt atesoraba ya una larga experiencia en la vida política de Estados Unidos.

En efecto, en 1884, tras perder a su madre y a su esposa en una misma jornada, T. Roosevelt abandonaba Nueva York y la política para asentarse en un rancho en la dura Dakota, donde sufriría la crudeza de la vida de frontera. Una vez rehecha su vida sentimental con un nuevo matrimonio, y su vuelta a la política, después de perder con 28 años las elecciones a alcalde de Nueva York, en 1889 fue nombrado Comisionado del Servicio Civil por la Administración Harrison, si bien en 1895 retornaba a su ciudad natal para presidir la Comisión de Policía, donde lucharía contra la corrupción, aumentando su ya extensa fama a nivel nacional. Pese a que T. Roosevelt mostraría en todo momento su rechazo ante las maniobras de la maquinaría partidista, ello no le impidió progresar de manera meteórica en política, y para 1897, con 39 años, era nombrado Subsecretario de Marina en la Administración McKinley. Pero de nuevo, su vida sufriría un giro inesperado un año más tarde con el comienzo de la guerra entre Estados Unidos y España.

1 Para consultar sus datos biográficos ver ZIMMERMANN, W. First great triumph. How five Americans made their country a world power, FSG Books, New York, 2002, p. 188-233, y GRAUBARD, S. The presidents. The transformation of the American Presidency from Theodore Roosevelt to George W. Bush, Penguin Books, New York, 2004,p. 85-127, BEALE, Howard K. Theodore Roosevelt and the Rise of America to Wolrd Power, John Hopkins University Press, Baltimore, 1956, MORRIS, Edmund The Rise of Theodore Roosevelt, Random House, New York, 2010 y ROOSEVELT, Theodore An autobiography, MacMillan, New York, 1913 (libro consultado en www.bartelby.com/55/) 
Cuba supuso para T. Roosevelt la oportunidad de poner en práctica su particular filosofía vital, y que como tendremos ocasión de comprobar en el siguiente apartado, aplicaba a todos los aspectos de su existencia, ya se tratase de su vida privada, de su actividad política o de su código ético. T. Roosevelt abandonó la seguridad de Washington, y se lanzó sin dudarlo a la primera fila de los combates, donde la suerte una vez más le sonrió, pues su valentía y la victoria estadounidense le brindarían la admiración y el respeto nacionales.

De regreso a Estados Unidos, T. Roosevelt no volvería a la Administración McKinley, sino que disputaría y ganaría las elecciones de 1898 a Gobernador del estado de Nueva York. De todos modos, sus constantes enfrentamientos con la maquinaria partidista y el mundo del capital, empujaron a T. Roosevelt a aceptar a regañadientes la nominación a candidato a Vicepresidente, acompañando a W. McKinley en las elecciones de noviembre de 1900. La victoria Republicana fue total, pero el segundo mandato del tándem McKinley-Roosevelt no perduraría.

El 6 de septiembre de 1901 el Presidente McKinley era disparado en un atentado, y tras ocho días de mala praxis médica fallecía, convirtiendo en realidad los temores de M. Hanna, quien hacía un año había advertido al resto del Partido que tan sólo una vida separaba a T. Roosevelt de la Presidencia. Con su llegada a la Casa Blanca, Estados Unidos por primera vez abandonaría su tradicional política exterior basada en un unilateralismo aislacionista, y la sustituiría por el internacionalismo que hoy por hoy todo el mundo conoce como la seña de identidad de Estados Unidos. Pero una transformación semejante no hubiese sido posible sin la determinación personal de T. Roosevelt, sin su particular visión de la vida en todas sus facetas, y que como se trasluce de éste pequeño bosquejo biográfico, informaba cada decisión que tomaba.

Conocer, aunque sea superficialmente, la vida de T. Roosevelt nos ayuda a comprender la renovación de la política exterior estadounidense que supuso su llegada a la Casa Blanca. Su intransigencia ante todo cuanto contradijera su peculiar forma de entender la vida, le llevaría igualmente a enfrentarse tanto a la maquinaría partidista, a la corrupción política y policial y a las injusticias sociales producidas por el desarrollo capitalista, como, en lo que será el objeto del presente estudio, a la tradicional política exterior de Estados Unidos, e incluso, una vez dejada la Presidencia, a la acción externa de su delfín W. H. Taft, y con ello al Partido Republicano que hasta el momento había sido su hogar político.

Para entender en toda su extensión el internacionalismo de T. Roosevelt he considerado oportuno dividir el presente trabajo en cuatro apartados, en el primero se analizará la política exterior de la Administración de T. Roosevelt, analizando el cambio que supuso respecto al pasado unilateralista de Estados Unidos; para enfrentar a continuación el internacionalismo conservador Republicano heredado de T. Roosevelt con el internacionalismo liberal democrático de W. Wilson, y así comprender mejor los diferentes enfoques con que Estados Unidos encaraba el in- 
ternacionalismo; en tercer lugar, se procederá a comparar el internacionalismo del Partido Republicano con el del T. Roosevelt progresivista ${ }^{2}$, para así entender la evolución del internacionalismo conservador al calor de los debates tanto internos como con el internacionalismo liberal democrático; finalmente, y a modo de conclusiones, se tratará de justificar la vigencia y oportunidad del pensamiento político de T. Roosevelt.

\section{EL INTERNACIONALISMO CONSERVADOR DE THEODORE ROOSEVELT}

Con T. Roosevelt, por primera vez y con voluntad firme, Estados Unidos participó en pie de igualdad con el resto de potencias en la resolución de las principales cuestiones internacionales, asumiendo un liderazgo mundial desconocido y esquivado hasta entonces por la clase política estadounidense. Con T. Roosevelt Estados Unidos ya no temería enredarse en los asuntos europeos ni se echaría para atrás a la hora de buscar monstruos en el exterior a los que destruir, la victoria sobre España supuso para el joven Presidente la confirmación de que Estados Unidos había asumido su mayoría de edad y con ello había llegado la hora de reconocer sus responsabilidades globales. Al pensar en términos mundiales, la política exterior de T. Roosevelt supuso un vuelco para el unilateralismo aislacionista, pues para cumplir con los nuevos objetivos Estados Unidos debía responder con nuevas tácticas y estrategias a los nuevos desafíos.

Conviene, antes de pasar a estudiar el internacionalismo de T. Roosevelt, detenerse brevemente en el unilateralismo aislacionista que prevalecía en la política exterior estadounidense hasta su llegada a la Casa Blanca, pues en Europa se

\footnotetext{
2 Nacido a finales del siglo XIX en las ciudades más industrializadas, el progresivismo tuvo su auge en Estados Unidos durante las dos primeras décadas del siglo XX. Su objetivo fue luchar contra los efectos más perversos del progreso, como las difíciles condiciones de vida en los suburbios o la corrupción municipal además de la reforma del sector laboral. Tras adquirir relevancia nacional, el progresivismo abrazó así mismo las causas de una reforma democrática del sistema electoral, de la justicia social y del interés público frente al poder creciente de las grandes corporaciones. Sus líderes eran jóvenes políticos como T. Roosevelt o R. La Follette, pertenecientes a la clase media acomodada y contrarios a las maquinarias regulares partidistas, que concebían su labor como un liderazgo benevolente para guiar a las masas a través de sus reformas, con una marcada predilección por la riqueza productiva sobre la acumulada por la especulación, no ya la corrupción, si bien tampoco veían con buenos ojos a los sindicatos, a quienes culpaban de fomentar la baja productividad y la violencia obrera, de hecho, el progresivismo tildaba a las clases sociales de artificiales. En todo caso, como solución su sistema se basaba más en términos morales que económicos, más en abstracciones que en casos prácticos, así, con T. Roosevelt se aprobarían varias leyes para regular el transporte por tren y la industria alimenticia, aunque otras medidas no serían aprobadas por la oposición del Congreso, entonces dominado por los Republicanos, y que bajo la presidencia de William Taft, paralizarían las reformas hasta la llegada de W. Wilson a la Casa Blanca. La fe norteamericana en la capacidad humana para cambiar el mundo junto con el rechazo a las mutaciones sociales que transformaban el sistema tradicional preindustrial, se unieron en el movimiento progresivista dotando al Estado de un cariz intervencionista antes desconocido y que para muchos tendría sus claras repercusiones en el New Deal de la década de 1930. MOWRY, G. The Era of Theodore Roosevelt 1900-1912, Harper \& Row, New York, 1958, p. 85-100 y ALLEN, F. L. The big change. America Transforms itself, 1900-1950, Harper \& Row Publishers, New York, 1952, p. 101.
} 
tiende a resumir la postura de Estados Unidos en su primer siglo de existencia, e incluso más allá, como de aislacionista, cuando dicho término en Estados Unidos se empezó a usar desde la década de 1890 en forma de insulto hacia quienes se oponían al intervencionismo en el exterior ${ }^{3}$. Así, más que de aislacionismo, desde la fundación de la nación hasta 1901, cabe hablar de unilateralismo aislacionista, entendiendo por tal la defensa del excepcionalismo norteamericano a través de una política exterior que, manteniendo alejada a la nación de los asuntos y enredos del resto de potencias, principalmente europeas, al mismo tiempo mantenía su libertad de acción al no enredarse en ningún tipo de alianza con terceros países.

Cabría recordar que la joven república luchaba aun por escapar al control del Reino Unido, si bien la Independencia le había otorgado la autonomía política, los líderes estadounidenses eran conscientes de que el control marítimo por parte de la flota británica y los dominios canadienses de la Corona amenazaban con prolongar la influencia inglesa sobre la vida política de la nación; para Mead ésta sería la principal cuestión política a resolver en la primera etapa de Estados Unidos, lograr una total y efectiva independencia del Reino Unido sin perjuicio de los equilibrios de poder europeos, es decir, mantener alejada a la Corona británica de los asuntos internos estadounidenses sin comprometer su posición en Europa ${ }^{4}$, para no beneficiar así a cualquier otra potencia, ya fuese Francia o Austria.

Fue G. Washington quien en su discurso de despedida había dejado como legado político su gran regla ${ }^{5}$, consistente en limitar al máximo las conexiones políticas con el resto de potencias, tratando de seguir el propio camino para evitar caer en el destino del resto de naciones. El objetivo era comenzar una nueva senda de la mano de la neutralidad en los conflictos internacionales, la aversión a las alianzas permanentes y el fomento de las relaciones pacíficas, sobre todo las comerciales, todo ello justificado por el excepcionalismo estadounidense nacido de la Independencia de la Corona Británica. La política exterior servía pues para apuntalar el excepcionalismo que definía domésticamente al carácter estadounidense, huyendo así de cruzadas peligrosas que pusieran en peligro esa misma libertad (ya fuese a través de las alianzas de las que abominaba Washington o de la participación americana en guerras innecesarias). A tenor de lo dicho habría que entender la gran regla de Washington, su afán por no enredar el destino norteamericano en los asuntos europeos, no tanto en clave de deriva aislacionista sino de un anhelo por conservar la autonomía en materia de política exterior, y de paso enfriar el debate interno entre los partidarios de Gran Bretaña y los de Francia, mientras la nación se fortalecía en el proceso.

\footnotetext{
${ }^{3}$ McDOUGALL, Walter A. Promised land, crussader State. The American encounter with the world since 1776, Mariner Books, New York, 1997, p. 39.

${ }_{4}$ MEAD, Walter Russell Special providence. American foreign policy and how it changed the world, New York, Ed. Routledge, 2002, p. 80.

5 WASHINGTON, George, Discurso de despedida de del 19 de septiembre de 1796, texto íntegro consultado en www.access.gpo.gov/congress/senate/farewell/sd106-21.pdf
} 
El unilateralismo aislacionista se vio pronto amenazado por los sucesos en Europa y sus consecuencias en el continente americano, pues al desmoronamiento irrefrenable del Imperio Español, y con él al de su estatus de gran potencia, se unían la Revolución Griega de 1821, que enfrentó las tesis de J. Q. Adams y J. Clay, éste partidario de intervenir a favor de los griegos y aquel de dejar que el ejemplo estadounidense guiase por sí sólo al mundo 6 , y la Restauración Europea, que amenazaba con intervenir en el continente americano a favor de las monarquías ${ }^{7}$. Tales sucesos acaecidos en Europa pero que tuvieron amplia repercusión en la política exterior de Estados Unidos, provocaron la reacción del Presidente Monroe en un claro intento por afirmar los valores norteamericanos frente a los europeos. Nacía así la Doctrina Monroe de $1823^{8}$, que al mismo tiempo que mantenía a Estados Unidos fuera de los asuntos europeos, se reservaba para sí el Continente Americano como su particular área de influencia, con la intención de preservar así el proyecto estadounidense libre de cualquier contaminación exterior.

El hecho desencadenante de la Doctrina Monroe fue el nacimiento de los nuevos Estados emancipados de la tutela española, percibida por Estados Unidos como ejemplo más representativo de la brutalidad monárquica, cuya leyenda negra no sería más que un ejemplo de su despotismo. Para la clase política estadounidense las independencias representaban la oportunidad de modelar el continente a su imagen y semejanza a través de la fuerza de su ejemplo, objetivo que no se lograría a menos que se impidiese la restauración imperial o la influencia de terceros (británicos o rusos). Con un mundo bajo la preeminencia del Imperio Británico, Estados Unidos trataba de sacar el mayor beneficio posible en su ascensión al rango de potencia mundial, eso sí, sin poner en peligro la arquitectura mundial, ya que sin la protección de la afinidad anglosajona sus objetivos se verían seriamente perjudicados (sin una potencia militar vecina digna de tal calificación, la Marina británica seguía siendo la mayor amenaza para Estados Unidos ${ }^{9}$ ). Así pues, la Doctrina Monroe respondía al afán norteamericano por dar mayor estabilidad al sistema americano de Estados, para de ese modo fortalecer su seguridad interna ${ }^{10}$.

Con la gran regla y la Doctrina Monroe el unilateralismo aislacionista se convirtió en el motor ideológico de la política exterior estadounidense por más de un siglo. En esencia, fue diseñado, e implementado eficazmente, para defender la independencia de una joven nación cuyo sistema político debía ser preservado tanto de la injerencia externa como de la contaminación también exterior, sin caer en la tentación de ligar su destino al de sistemas políticos contrarios a los principios

6 MEAD, op. cit., p.4

7 Ibíd., p. 151.

8 MONROE, James, Séptimo mensaje anual del 2 de diciembre de 1823, texto consultado en www.presidency.ucsb.edu/ws/index.php?pid=29465\&st=spain\&st1=

9 HERRING, George C. From Colony to Superpower. U. S. Foreign Relations since 1776, Oxford University Press, New York, 2008,p. 57.

10 Una constante, la de entender la seguridad propia como la seguridad primero continental, y luego mundial, que trasluce tanto el carácter globalizador de la política exterior de Estados Unidos como su fe en la exportabilidad de su modelo político. 
y valores democráticos y republicanos erigidos en Estados Unidos. Pero en 1901, tras la victoria sobre España, Estados Unidos hacía tiempo que había dejado de ser la pequeña y débil nación formada por ex colonias, habiéndose convertido en una potencia mundial de primer rango, y por tanto, lo que había servido en 1800 difícilmente podría seguir siendo útil en 1900, pues Estados Unidos, con un imperio recién conquistado y unos crecientes intereses económicos globales, no podía seguir dando la espalda a los problemas mundiales, no al menos sin ver peligrar sus intereses nacionales, circunstancia que hasta el momento no se había dado en la historia del país.

La reorganización ideológica promovida por T. Roosevelt trataba de salvar la distancia entre la realidad de unos Estados Unidos convertidos en potencia mundial y la pervivencia de una política exterior diseñada para salvaguardar la independencia de una pequeña nación recién nacida. El Internacionalismo se impuso en Estados Unidos como una necesidad histórica, derivada de la evolución misma de la nación, pero sin el genio particular de T. Roosevelt hubiese tardado mucho más tiempo en consolidarse, además se hubiese perdido el tinte conservador que tanto influiría en el Internacionalismo Republicano de entre guerras.

De todos modos, el que T. Roosevelt quisiera dotar a la política exterior estadounidense de una clara dimensión mundial no hubiese sido suficiente para que el Internacionalismo conservador se convirtiera en el primer ensayo internacionalista de la historia de Estados Unidos. Para ello era además imperativo que aquel contase con una base ideológica capaz de dotar de cierta coherencia intelectual a dicho impulso internacionalista, y que al mismo tiempo fuera implementada en la práctica. Al no establecer una clara distinción entre los valores que aplicaba en su vida ordinaria y los proclamados en su práctica política, T. Roosevelt creó una base ideológica de sencillo reconocimiento que dotó a su Internacionalismo conservador de la necesaria consistencia programática para convertirse en una verdadera revolución dentro de la política exterior estadounidense. Si el realismo, junto al internacionalismo, son las notas predominantes de su ideario, su insistencia en transformar las palabras en actos ha facilitado enormemente la tarea de rastrear las huellas del Internacionalismo conservador en la práctica.

Al llegar a la Casa Blanca T. Roosevelt, un hombre tan activo política y militarmente como profundo pensador con numerosas inquietudes intelectuales, ya había desarrollado el grueso de sus valores y creencias. Para el nuevo Presidente el modo en que un hombre debía comportarse en su vida cotidiana no difería en exceso del modo en que una nación debía encarar sus relaciones con el resto de Estados, lo que aplicado a Estados Unidos supuso una verdadera revaluación de las políticas seguidas hasta el momento, no en vano, todo el esfuerzo de T. Roosevelt se puede resumir en un intento para que el pueblo estadounidense asumiese las responsabilidades inherentes al nuevo status de la nación, y así ocupar el lugar protagónico que, según él mismo, Estados Unidos se merecía. 
En 1901 dicho plan suponía realmente el abandono de parte de la tradición política estadounidense y el remodelado y adaptación del resto. Como veremos en las páginas siguientes, si Estados Unidos aumentaba sus compromisos internacionales para jugar un papel más activo en la escena mundial, la gran regla washingtoniana se convertía más que en una guía, en un impedimento para alcanzar los objetivos deseados, ello no equivalía a descartarla por entero, pero sí a matizarla, pues aunque a principios del siglo XX en Estados Unidos aun era impensable su participación en una alianza duradera, para T. Roosevelt ello no era obstáculo para que la nación sí participase en los principales foros de negociación internacional del momento, algo completamente novedoso en la estrategia norteamericana. Lo mismo cabe afirmar de la Doctrina Monroe, que si bien siguió siendo un pilar central de la política exterior de la Administración de T. Roosevelt, éste no dudaría en añadir su propio corolario a la misma para así adaptarla a los nuevos tiempos.

Como ya se ha señalado, el Internacionalismo conservador se debió principalmente al genio creador de T. Roosevelt, pero el Presidente contó con la ayuda inestimable de su equipo gubernamental y amigos, entre los que destacaron John Hay o Elihu Root, además del almirante Mahan o el Senador H. C. Lodge. J. Hay fue esencial como Secretario de Estado y artífice de la política de Puertas Abiertas hacia China ${ }^{11}$; E. Root, Secretario de Guerra y Estado, ayudó a T. Roosevelt a la extensión de la figura del arbitrio internacional en la resolución de disputas entre naciones ${ }^{12}$; H. C. Lodge, amigo personal de T. Roosevelt y miembro influyente del Congreso, apoyó en todo momento el internacionalismo conservador del Presidente en el Senado'3; mientras que Mahan apuntalaría la justificación para el reforzamiento de la Marina estadounidense tan querido a T. Roosevelt, así, Mahan escribiría La influencia del poder naval en la Historia 1660-1783 con la intención de mostrar la influencia del poder marítimo en los grandes asuntos mundiales, a través de los numerosos ejemplos históricos estudiados en sus catorce capítulos, desde la guerra angloholandesa de 1665-1667 hasta la campaña naval británica de las Indias Orientales de 1783, pasando por la guerra de sucesión española de 1702-1713 o la Guerra de los Siete Años ${ }^{14}$, así, su defensa de una fuerza naval capaz de asegurar el nuevo status de potencia a Estados Unidos le acercaría a políticos, que como Theodore Roosevelt, también abogaban por un rearme americano, desde entonces se mantendrían unidos en su afán por dotar a la Marina estadounidense de las capacidades necesarias para desempeñar su rol, juzgado imprescindible, en el diseño de la política nacional.

11 Para el estudio la estrategia de Puertas Abiertas ver ZIMMERMANN, Warren First great triumph. How five Americans made their country a world power, FSG Books, New York, p. 443-452.

12 Ibíd., p. 139.

13 WILDMAN, Edwin Famous leaders of character in America, from the latter half of nineteenth century; the life stories of boys who have impressed their personalities on the life and history of the United States, The Page Company, Cap. XIV, Boston, 1922.

14 MAHAN, Alfred Thayer The Influence of Sea Power Upon History, 1660-1783, Little, Brown and Company, Boston, 1890, p. 1. 
En todo caso, sería el propio T. Roosevelt el padre intelectual del primer ensayo internacionalista en la política exterior estadounidense, puesto que los valores y creencias de aquel formaron los axiomas principales de éste, además, no hay que olvidar que en calidad de Presidente, T. Roosevelt era el único capaz de llevar a la práctica el ideario internacionalista conservador, y desde que alcanzara tal cargo, y pese a la oposición que surgiría ante sus políticas, no cesó ni un solo instante de aplicarlo con todo su celo.

A la hora de enumerar las notas principales del internacionalismo conservador conviene no olvidar que todas ellas forman un conjunto interrelacionado, y en numerosas ocasiones comparten elementos, pues cada componente nos conduce necesariamente al siguiente, lo que da idea de la coherencia teórica del mismo. Por tanto, pasemos ahora a ver cuáles son las notas principales del Internacionalismo conservador desarrolladas por T. Roosevelt:

- Nacionalismo democrático: para T. Roosevelt «el hombre que más puede hacer en este país es y debe ser el hombre cuyo americanismo es más sincero e intenso ${ }^{15}$, es decir, la primera condición de un buen ciudadano estadounidense era amar a la patria. Para Roosevelt, el sentido de su amplio americanismo se traducía en la contraposición de éste con el localismo, el cosmopolitismo y la inmigración no asimilada; respecto al localismo, también conocido por parroquianismo o provincianismo, Roosevelt diría que «el patriotismo del pueblo o del campanario es malo » ${ }^{16}$, el verdadero es el que se tiene por el conjunto de la nación; en cuanto al cosmopolitismo aquí Roosevelt sí que carga las tintas contra sus defensores pues «nada descalificará más rápido y de forma más segura a un hombre de hacer un buen trabajo en el mundo que la adquisición de ese hábito de mente que sus posesores llaman cosmopolitismo ${ }^{17}$. De todas formas, ello no implicaba un rechazo del internacionalismo, ni mucho menos, sólo que para T. Roosevelt antes que el resto de principios políticos debía encontrarse el amor por la patria, pues «no soy un defensor de un loco cosmopolitismo. Creo que un hombre debe ser un buen patriota antes de que pueda, y como único modo de ser, un buen ciudadano del mundo ${ }^{18}$. El nacionalismo de T. Roosevelt es indisociable de la naturaleza democrática de su sistema político, el que Estados Unidos fuese una república democrática era el hecho diferenciador que debía conferir al pueblo estadounidense no sólo ventajas y beneficios personales, sino un lugar preponderante en los

15 ROOSEVELT, Theodore, «True Americanism», artículo aparecido en abril de 1894 en la revista The Forum Magazine, texto consultado en www.theodore-roosevelt.com/trbiogf.html

16 Ibíd.

17 Ibíd. ya que sin duda «es cincuenta veces mejor ser un americano de primera clase que un francés o inglés de imitación de segunda clase [...] ninguna otra tierra ofrece tales posibilidades gloriosas al hombre capaz de sacar ventaja de ellas, como hacen los nuestros, sigue siendo verdad que nadie de nuestro pueblo puede hacer ningún trabajo con dignidad a menos que lo haga ante todo como americano [...]por el contrario, es en esas profesiones donde nuestra gente ha peleado al máximo para amoldarse a formas europeas convencionales donde ellos han tenido menos éxito", Ibíd.

18 R OOSEVELT, Theodore, «The Man in the Arena» discurso pronunciado el 23 de abril de 1910 en la Sorbona de París, párrafo 24, texto consultado en www.theodore-roosevelt.com. 
asuntos mundiales con tal de que asumiera las responsabilidades implícitas en su propia condición democrática, es decir, Estados Unidos era poderoso no por sus bienes materiales o su poder militar, sino por encarnar la primera república democrática de la era moderna ${ }^{19}$. Como se observa, la fe de Roosevelt en la libertad se encuentra en clara consonancia con la tradición liberal de la política estadounidense, de hecho, una característica de su patriotismo es la constante referencia a la tradición para justificar sus argumentos, en particular y muy especialmente, cuando intentó justificar su programa expansionista T. Roosevelt apelará a la tradición libertadora de los padres fundadores y al papel jugado por Lincoln y Grant durante la guerra civil $^{20}$, y buscará en la conquista del continente norteamericano un antecedente de la lucha por la civilización emprendida por su Gobierno y el de su antecesor en las nuevas colonias ${ }^{21}$, igualmente citará de nuevo a Lincoln cuando intentó explicar y legitimar su visión de la relación capital-sociedad ${ }^{22}$.

- Carácter. la compleja personalidad de T. Roosevelt, su duro aprendizaje infantil y la superación de una debilidad física dejaron una impronta imborrable en su concepción política, a lo que sumado a sus firmes creencias religiosas dieron como resultado la defensa de un modelo de compromiso responsable y constante trabajo que el propio Theodore explicaría así

«para hacer nuestra tarea [...] el camino seguro para tener éxito es [...] el espíritu de devoción al deber, de la determinación a repartir con justicia, con imparcialidad y sin miedo a todos los hombres, y de la resolución firme a nunca abandonar ninguna tarea una vez comenzada hasta que no sea llevada a una conclusión exitosa y triunfante» ${ }^{23}$

También el hombre con carácter debe ser para T. Roosevelt un hombre de acción, capaz de realizar sus ideales y demostrar con la práctica cuanto promete de palabra, es esa permanente apelación a cumplir con la tarea asignada lo que para T. Roosevelt probaba el carácter tanto personal como nacional, ya que «es sólo a través de la lucha, del esfuerzo duro y peligroso que ganaremos finalmente

\footnotetext{
19 «Nuestro país —ésta gran república - no significa nada a menos que signifique el triunfo de la democracia, el triunfo del gobierno popular, y, a largo plazo, de un sistema económico bajo el que a cada hombre pueda garantizársele la oportunidad de mostrar lo mejor que hay en sí mismo. Por ello es por lo que la historia de América es ahora el hecho central de la historia del mundo, ya que el mundo ha puesto su cara con esperanza hacia nuestra democracia [...] mis queridos compatriotas, cada uno de vosotros porta en sus hombros no sólo la carga de hacer lo correcto por el bien de nuestro país, también la carga de hacerlo bien y de ver que esta nación hace lo correcto por el bien de la humanidad», ROOSEVELT, Theodore, «The new nationalism» discurso pronunciado el 31 de agosto de 1910, texto consultado en www.theodore-roosevelt.com.

20 ROOSEVELT, Theodore, ver «The Expansion and Peace», artículo aparecido el 21 de diciembre de 1899 en Independent, párrafo 5, articuloo consultado en www.batleby.com/58/2.html.

21 ROOSEVELT, Theodore, «The Man in the Arena» discurso pronunciado el 23 de abril de 1910 en la Sorbona de París, párrafo 2, texto consultado en www.theodore-roosevelt.com.

22 ROOSEVELT, Theodore, ver «The new nationalism» discurso pronunciado el 31 de agosto de 1910, párrafo 4, texto consultado en www.theodore-roosevelt.com.

${ }^{23}$ ROOSEVELT, Theodore, «Grant» discurso pronunciado el 27 de abril de 1900 en Galena, Illinois, texto consultado en www.bartleby.com/58/13.html
} 
el objetivo de la verdadera grandeza nacional»24. Además, para Roosevelt el carácter era inseparable de la moral, y sin duda la cualidad más valiosa en un hombre, pues «a largo plazo, en la gran batalla de la vida, ninguna brillantez del intelecto, ninguna perfección del desarrollo corporal, contarán frente a la suma de virtudes, activas o pasivas, de las cualidades morales, que agrupamos bajo el nombre de carácter»25. Tenacidad, honestidad, sentido moral, guía religiosa, predisposición a la acción, todo ello confiere al carácter definido por Roosevelt unas características propias que impregnan toda su teoría política ${ }^{26}$.

- Realismo: en éste punto T. Roosevelt comienza a separarse de la tradición política estadounidense, ya que si hasta el momento ésta había permanecido anclada en un idealismo que permitía a la nación mantenerse alejada de los asuntos mundiales ${ }^{27}$, con él en la Presidencia Estados Unidos tendrá su primera experiencia con una estrategia exterior de marcado sesgo realista. Para el vigésimo sexto Presidente estadounidense «tenemos que encarar los hechos como son. No debemos caer en un optimismo loco ni sucumbir a un pesimismo innoble y tímido. Nuestra nación es una entre las naciones de la tierra que tiene en sus manos el destino de los años venideros ${ }^{28}$. Una consecuencia clave de su realismo le llevaba a no aceptar acuerdos de paz a cualquier precio, al igual que su amigo Mahan quien denunciaba «el peligro de la abogacía indiscriminada de la paz a cualquier precio» ${ }^{29}$, pues ello "conducirá al hombre a mezclarse con la injusticia, a comprometerse con lo equivocado, disparando a su conciencia con la creencia de que la guerra es tan mala que más allá de ella ningún otro mal está equivocado»30, de hecho T. Roosevelt creía firmemente que «la cobardía no promueve la paz, y el gran mal de la guerra puede ser menos malo que llorar ante la injusticia»31, de ahí

24 ROOSEVELT, Theodore, «The Strenuous Life» discurso pronunciado el 10 de abril de 1899 en Chicago, párrafo 2, texto consultado en www.bartleby.com/58/1.html

25 ROOSEVELT, Theodore, «Character and Succes» artículo publicado el 31 de mayo en Outlook, párrafo 2, texto consultado en www.bartleby.com/58/6html.

${ }_{26}$ Como él mismo no se cansara de predicar «la doctrina de la vida activa, la vida de la labor y el esfuerzo, del trabajo y la lucha, predicar la forma más alta de éxito que procede, no del hombre que desea la mera paz fácil, sino del hombre que no se acobarda ante el peligro, ante la dificultad, o ante el trabajo amargo, y que por encima de ello gana el espléndido triunfo final», ROOSEVELT, Theodore, «The Strenuous Life» discurso pronunciado el 10 de abril de 1899 en Chicago, párrafo 1, texto consultado en www.bartleby.com/58/1.html.

27 Si por un lado tal postura había sido coherente con la debilidad de Estados Unidos respecto a las principales potencias europeas, a partir del final de la Guerra Civil, cuando Estados Unidos ya era una potencia mundial, el rechazo a inmiscuirse en los asuntos mundiales se nutrió principalmente de la tradicional aversión norteamericana a la política de poder europea, en contraste con las prácticas democráticas legadas por los padres fundadores de Estados Unidos, de ahí que sostenga que hasta la llegada de T. Roosevelt a la presidencia, fuese el idealismo, más que el realismo, el que alimentara al unilateralismo aislacionista.

28 ROOSEVELT, Theodore, «True Americanism», artículo aparecido en abril de 1894 en la revista The Forum Magazine, párrafo 4, texto consultado en www.theodore-roosevelt.com/trbiogf.html.

29 ROOSEVELT, Theodore, ver «The Expansion and Peace», artículo aparecido el 21 de diciembre de 1899 en Independent, párrafo 2, artículo consultado en www.batleby.com/58/2.html

30 lbíd.

31 Ibíd. 
la necesidad, y hasta el deber, de prepararse para lo peor, es decir, de tener unas fuerzas armadas capaces de defender todo aquello en lo que se cree.

- Preparación militar. el que T. Roosevelt diese un nuevo rumbo a la política exterior estadounidense no implicaba que desdeñara por entero su acervo tradicional, especialmente en el presente apartado, pues si bien el aumento del gasto militar suponía alejarse del temor atávico hacia los ejércitos permanentes de la sociedad norteamericana, trató siempre de ubicarlo en el contexto de la tradición política nacional, así no dudaba en citar a Washington a la hora de justificar su aumento del gasto militar, pues el primer Presidente de Estados Unidos ya había aseverado que «estar preparados para la guerra es el modo más efectivo para promover la paz»32. Para Roosevelt Estados Unidos nunca había estado preparado para las guerras en que había participado, debido a su ánimo poco guerrero, lo que en principio pudiera parecer una cualidad positiva, podría suponer más una carga para el futuro de la nación. Por lo tanto Estados Unidos debía armarse para evitar ser presa de la guerra, además, T. Roosevelt consideraba una ofensa al honor nacional no estar dispuesto a luchar por ella, para él «ninguna nación debe emprender la guerra caprichosamente, pero ninguna nación debe evitarla nunca al coste de perder su honor nacional ${ }^{33}$, lo que concuerda totalmente con su patriotismo y su peculiar carácter. Lo fundamental era que Estados Unidos estuviese preparado militarmente para no repetir los errores del pasado, como se demostró en la guerra de 1812 contra Inglaterra donde «nuestra Armada ganó por su preparación y por su espléndida tripulación y armamento que han sido transmitidos como tradición en el servicio ${ }^{34}$. En todo caso, consciente de que tal postura chocaba con el tradicional rechazo del pueblo estadounidense a la constitución de grandes ejércitos permanentes, T. Roosevelt defendía que Estados Unidos con una población de 70 millones de habitantes no tenía nada de que temer de un ejército de 100.000 efectivos, «de los que tres cuartos serán emplazados en ciertas islas lejanas, en fortalezas costeras y en reservas indias ${ }^{35}$, y teniendo siempre presente que «es apenas necesario para mí repetir que creo en un ejército eficiente y una Armada lo suficientemente grande como para asegurarnos en el extranjero ese respeto que es la garantía más segura para la paz»36. Así pues, teniendo en cuenta que T. Roosevelt veía en la preparación militar no sólo un medio para mantener a Estados Unidos capacitado para encarar futuros desafíos, sino como una medida para evitar verse envuelto en posibles guerras, no es de extrañar, dada también su pre-

32 ROOSEVELT, Theodore, discurso pronunciado en la Escuela Naval de Guerra el 2 de julio de 1897, texto consultado en www.theodore-roosevelt.com

33 Ibíd.

34 ROOSEVELT, Theodore, «Military Preparedness and Unpreparedness», artículo publicado en noviembre de 1899 en Century, texto consultado en www.bartleby.com/58/11.html ya que «de todos modos, todo ello, aunque indispensable en la base, no significaría nada para la eficacia de la Marina sin los años de cuidadosa preparación y entrenamiento", Ibíd.

35 ROOSEVELT, Theodore, «The Strenuous Life» discurso pronunciado el 10 de abril de 1899 en Chicago, párrafo 10, texto consultado en www.bartleby.com/58/1.html.

36 ROOSEVELT, Theodore, ver «The new nationalism» discurso pronunciado el 31 de agosto de 1910, párrafo 25, texto consultado en www.theodore-roosevelt.com. 
dilección por la Marina, que defendiera un aumento de la misma ${ }^{37}$. Una de las razones capitales esgrimidas por $\mathrm{T}$. Roosevelt para legitimar el aumento de las capacidades de la Armada estadounidense ${ }^{38}$ fue sin duda la expansión de los intereses nacionales hacia el Pacífico ${ }^{39}$, por ello era partidario de anexionarse Hawaii o al menos convertirlo en un protectorado estadounidense, pues consciente del peligro del expansionismo japonés en el Pacífico, veía en dichas islas un medio para controlarlo, siguiendo aquí los postulados de Mahan, permitiendo así a Estados Unidos tener una mayor presencia en Asia y dominar el Caribe, con la construcción del Canal interoceánico de Panamá ya en ciernes. Como vemos, la preparación militar sirvió a T. Roosevelt para justificar, dada su presunta utilidad para la paz, tanto la modernización de la Marina estadounidense como la expansión de sus intereses al Pacífico, éste último aspecto nos introduce en otro de los componentes principales de su ideario, su internacionalismo, que como veremos no sólo se nutría de un componente geoestratégico a la hora de legitimarlo, sino que debido a la naturaleza democrática de Estados Unidos y al alto grado de responsabilidad de su carácter, contenía también un aspecto misionero o civilizador esencial a la hora de entender el tipo de política que T. Roosevelt se proponía entablar en sus relaciones con otros pueblos, en especial con los menos modernizados.

- Internacionalismo: todos y cada uno de los aspectos hasta aquí analizados nos conducen al presente apartado, ya que si se combinan entre sí nos asalta como consecuencia lógica que $\mathrm{T}$. Roosevelt se desvinculase del tradicional unilateralismo aislacionista de la política exterior estadounidense al reemplazarlo por su particular internacionalismo de tinte conservador. Su carácter propenso a la acción responsable, su nacionalismo democrático, su concepción realista de la vida y su apoyo a la modernización de la Armada no pueden entenderse sin una profusa participación de Estados Unidos en la escena mundial, es decir, el internacionalismo es el que da sentido a todas ellas al conectarlas entre sí y dotarlas de una finalidad común. El internacionalismo confiere a todos ellos una dimensión global capaz de legitimar sus implicaciones en base a un programa coherente, cuya finalidad es colocar al país al lado de las grandes potencias que dominan el mundo, y rescatar de paso para la humanidad a unos Estados Unidos cuya misión puede reportarle muchos beneficios de la mano de su naturaleza democrática, su fuerte personalidad, su visión desapasionada de la realidad y su renovada fuerza

37 Para T. Roosevelt era esencial que el país continuase con la modernización de su flota iniciada por el presidente Chester Arthur (1881-1885), cuyo Secretario de Marina W. Chandler inició la construcción de nuevos barcos y la reparación de los más antiguos, viendo en esas medidas el comienzo de la victoria sobre España en 1898, ROOSEVELT, Theodore, «Military Preparedness and Unpreparedness», artículo publicado en noviembre de 1899 en Century, párrafo 11, texto consultado en www.bartleby.com/58/11.html.

${ }_{38}$ Para ver las medidas implementadas por T. Roosevelt al respecto una vez alcanzada la presidencia, consultar la p. 15 del presente trabajo.

39 ROOSEVELT, Theodore, «Obstacles to Inmediate Expansion», carta escrita a A. T. Mahan de 1897, texto consultado en www.theodore-roosevelt.com, en 1897 escribía a A. Mahan que «comprendo del todo la inmensa importancia de la costa del Pacífico», Ibíd. 
militar. Para T. Roosvelt Estados Unidos no debía contentarse con su propio desarrollo nacional, sino que debía ejecutar también su papel internacional, pues

«mientras que la primera tarea de una nación está dentro de sus fronteras, no por ello estará absuelta de encarar las tareas en el mundo como un todo, y si se niega a ello, sólo pierde el derecho a luchar por un lugar entre los pueblos que modelan el destino de la humanidad»40

Estados Unidos, en su propio beneficio, tenía la obligación de participar en los asuntos mundiales, más aun teniendo en cuenta sus nuevos compromisos adquiridos tras la guerra con España en 1898. Las nuevas posesiones, más allá de conceder a Estados Unidos un nuevo status imperial del que carecía a nivel internacional, también suponían para T. Roosevelt que la nación encarase por primera vez allende sus fronteras una misión civilizadora de consecuencias trascendentales, su internacionalismo añadiría un componente misionero o civilizador que justificaba la presencia y participación de Estados Unidos en los asuntos internos de otros pueblos. Teniendo a Gran Bretaña siempre presente como modelo, veía en su dominio sobre India y Egipto un claro ejemplo de beneficio mutuo, pues si Londres afianzó sus cualidades de liderazgo sobre sus colonias, ejercitándose de ese modo en su papel de gran potencia, éstas se beneficiaban con el avance de la civilización que suponía la presencia británica, por ello creía firmemente que Estados Unidos debía cumplir su papel en Filipinas, ya que

«el trabajo debe ser hecho, no podemos escapar de nuestra responsabilidad; y si somos dignos de nuestro ingenio, debemos estar agradecidos de la oportunidad de hacer el trabajo- agradecidos de la oportunidad de demostrarnos a nosotros mismos a la altura de una de las grandes tareas que impone la moderna civilización» ${ }^{41}$

El punto clave de su razonamiento se encontraba en su celo civilizador, pues para T. Roosevelt «toda expansión de la civilización favorece a la paz. En otras palabras, toda expansión de una gran potencia civilizada significa una victoria para la ley, el orden y la justicia. Este ha sido el caso en toda expansión durante el presente siglo» ${ }^{42}$. Por lo tanto, según T. Roosevelt Estados Unidos tenía la responsabilidad de llevar la paz a los pueblos menos civilizados, donde reinaba la barbarie, merced a su injerencia civilizadora, lo que sin duda implicaba que la nación se involucrase de manera activa en los asuntos mundiales, ocu-

40 Ibíd.

41 Ibíd.

42 ROOSEVELT, Theodore, ver «The Expansion and Peace», artículo aparecido el 21 de diciembre de 1899 en Independent, párrafo 3, artículo consultado en www.batleby.com/58/2.html de ello se benefician todas las partes, pues «en todo caso el resultado prueba que la potencia en expansión estaba haciendo un trabajo de civilización más grande e importante de lo que podría haberse hecho mediante una potencia temporal», Ibíd. con el objetivo final puesto en «que un hermoso punto más de la superficie de la tierra pueda ser arrebatado de las fuerzas de la oscuridad. Fundamentalmente la causa de la expansión es la causa de la paz», Ibíd. La negrita es mía. 
pando una posición prominente entre las grandes potencias. Si la misión civilizadora debía regir las relaciones con los pueblos menos avanzados, respecto al resto de naciones con las que Estados Unidos compartía un nivel similar de desarrollo, T. Roosevelt era partidario de mantener un equilibrio pacífico basado en la resolución negociada de las controversias que pudieran surgir entre ellas, por ello proponía el arbitrio como mejor modo de lograrlo, eso sí, sin que ello afectase a la modernización de la Armada estadounidense ${ }^{43}$. Pero la animadversión de $\mathrm{T}$. Roosevelt hacia los tratados injustos le llevaba a recalcar una vez más la necesidad de no descuidar «el garrote» que le hizo famoso, y que tanto ha distorsionado su imagen ${ }^{44}$, de hecho, para T. Roosevelt, el arbitrio no era el único instrumento al alcance de los pueblos civilizados para la resolución pacífica de las controversias, junto a él se encontraban el recurso al Tribunal de la Haya y sus conferencias, con el Tribunal Supremo estadounidense en mente como modelo, y al que tantos esfuerzos dedicaría durante su presidencia, involucrando con ello a Estados Unidos en una instancia judicial internacional, lo que sin duda suponía toda una novedad en su historia, pero sobre todo, como tercer método, T. Roosevelt lanzaría la idea de «formar una Liga de la Paz, no sólo para mantener la paz entre ellas (las grandes potencias honestamente interesadas en la paz), sino también para prevenir, por la fuerza si fuera necesario, que sea rota por otros ${ }^{45}$, pero $\mathrm{T}$. Roosevelt era consciente de que la principal dificultad del proyecto radicaba en «la falta de cualquier poder Ejecutivo, de cualquier poder de policía para reforzar los decretos de la corte» ${ }^{46}$, por ello «cada nación debe mantenerse bien preparada para defenderse hasta el establecimiento de alguna forma de poder internacional de policía, competente y dispuesto a prevenir la violencia entre las naciones ${ }^{47}$ y para T. Roosevelt, en su momento, el mejor modo de lograrlo sería a través de «alguna combinación entre esas grandes naciones que sinceramente desean la paz y no tienen ningún deseo de cometer agresiones ${ }^{48}$. Como vemos, su realismo y su particular concepción evolutiva de los pueblos le llevaban a reconocer que por el momento esa Liga de la Paz fuese sólo un ideal a alcanzar, pues a falta de un poder coercitivo global que hiciese ejecutar la ley internacional, dicho proyecto no sería más que una qui-

43 ROOSEVELT, Theodore, discurso pronunciado en la Escuela Naval de Guerra el 2 de julio de 1897, párrafo 4, texto consultado en www.theodore-roosevelt.com. pues aunque «el arbitrio es una cosa excelente, pero a la postre aquellos que desean ver a este país en paz con las naciones extranjeras serán sabios si colocan su confianza en una flota de primera categoría de acorazados de primera clase mejor que en cualquier tratado de arbitrio que la inteligencia del hombre pueda idear....Más aun, mientras somos sinceros y firmes en nuestra defensa de la paz, no debemos olvidar que una paz innoble es peor que cualquier guerra», Ibíd.

44 ROOSEVELT, Theodore, discurso de aceptación del Premio Nobel de la Paz del 10 de mayo de 1910, párrafo 1, texto consultado en www.theodore-roosevelt.com pero de todos modos, ello nunca implicó un rechazo de plano de la idea de la negociación, pues para él «todas las comunidades civilizadas tendrían que tener tratados de arbitraje efectivos entre ellas», Ibíd.

45 Ibíd.

46 Ibíd.

47 Ibíd.

48 Ibíd. 
mera, o peor aun, letra muerta que diese pie a mayores injusticias ${ }^{49}$. Es decir, T. Roosevelt reconocía aun la preeminencia de la soberanía Estatal y del interés nacional sobre un incipiente orden mundial basado en leyes y organizaciones internacionales, y es a partir de éste punto de vista donde hay que colocar al resto de principios hasta aquí estudiados, pues para T. Roosevelt la democracia estadounidense debe ser preservada a través de un carácter fuerte y realista tendiente siempre a relacionarse pacíficamente con el resto de países, pero siendo a la vez capaz de defender sus intereses, incluso a través de la fuerza si fuera necesario, y ello era así ante la ausencia de un ordenamiento a escala mundial capaz de armonizar los comportamientos de los Estados, pues a diferencia de Estados Unidos, donde los diferentes estados se habían asociado en torno a la Unión, a nivel mundial las naciones aun se guiaban por sus exclusivos y excluyentes intereses nacionales, de ahí que Estados Unidos debiera alcanzar una posición de preeminencia que le permitiese defender sus intereses, tanto en su propio beneficio, como por el bien de la humanidad, al encarnar su pueblo los ideales democráticos. Así pues, su internacionalismo es conservador en la medida en que su afán por colocar a Estados Unidos entre las grandes potencias, haciendo así que su nación participara de forma activa en los asuntos mundiales de mayor trascendencia, y su creencia en un orden futuro de colaboración internacional institucionalizada, no le impedía reconocer al mismo tiempo que por el momento los Estados aun se regían por el clásico interés nacional, lo que en cierta medida obligaba a Estados Unidos a jugar el mismo juego que el resto de grandes potencias en la gran partida por el poder mundial de finales del siglo XIX e inicios del $X X$.

Dichas notas principales se tradujeron en la práctica en una serie de medidas encaminadas a hacer de Estados Unidos una potencia activa dentro del orden internacional de inicios del siglo XX, y que podemos resumir en:

- Defensa nacional: al igual que el resto de su equipo de Gobierno, T. Roosevelt siempre abogó por la necesidad de una Marina capaz de servir a los nuevos intereses globales de Estados Unidos; continuó con el rearme naval hasta el punto de convertir la flota estadounidense en la segunda del mundo sólo por detrás de la británica, cuando al principio de su Presidencia era la quinta por detrás de británicos, franceses, alemanes y rusos, de hecho, desde 1900 hasta 1905 Estados Unidos habría construido cinco acorazados, cuatro cruceros, cuatro monitores y 34 destructores y botes torpederos, de ese modo, la Marina para 1907 había doblado su tamaño desde su llegada al poder ${ }^{50}$. Así, en 1907 ordenó a su flota (la lla-

49 ROOSEVELT, Theodore, «The Man in the Arena», ob.cit. «la ley internacional, creo, conforme pasen las generaciones, crecerá más fuerte hasta que un día u otro se desarrolle el poder de ser respetada. Pero hasta entonces está sólo en su periodo formativo. Hasta entonces, como una regla, cada nación tiene la necesidad de juzgar por sí misma en materias de vital importancia entre ella y sus vecinos [...] como último recurso deben poseer tanto el poder como la voluntad de guardad rencor por las ofensas de otros», Ibíd.

50 MORRIS, Edmund Theodore Rex, Random House, New York, 2010, p. 334 y 485. 
mada Gran Flota Blanca) partir en una gira mundial de catorce meses con el propósito de mostrar al mundo el nuevo poder estadounidense ${ }^{51}$, y así añadir una proeza a su segundo mandato equiparable al acuerdo sobre el Canal de Panamá del primero ${ }^{52}$, a lo que hay que sumar varios objetivos soterrados, como el presionar a Japón, el ganar apoyo popular tanto a la construcción del Canal de Panamá como al aumento de la Armada, así como brindarle a la misma una inmejorable ocasión de entrenamiento ${ }^{53}$. Para el propio T. Roosevelt dicha gira mundial, que organizó pese a la oposición de numerosos sectores de la sociedad estadounidense, fue trascendental pues benefició en gran medida a la Armada, aumentó el interés y entusiasmo populares por la misma y contribuyó a la aceptación internacional de la presencia de Estados Unidos en el Pacífico ${ }^{54}$. La gira mundial de la Armada reflejaba uno de los aspectos cardinales de la personalidad de T. Roosevelt, como ya hemos visto, Theodore prefería encarar los problemas antes que huir de ellos, lo que a nivel de Presidente lo tradujo en que «en política internacional el principio del que nunca nos desviamos fue que la nación se comportase con otras naciones como un hombre fuerte, honorable y honrado se comporta al tratar con sus prójimos ${ }^{55}$, y como quiera que entre las naciones no existía una policía mundial que haga cumplir las leyes internacionales, Estados Unidos debía protegerse si no quería seguir el ejemplo chino, una nación poderosa a merced de la voluntad de otros, no en vano «ninguna nación puede reclamar derechos sin reconocer los deberes que acompañan esos derechos. Es algo despreciable para una gran nación mantenerse impotente en la acción internacional, ya sea por cobardía o pereza o por pura ineficacia y falta de voluntad de mirar hacia el futuro» $\$ 6$;

- Pacífico: la adquisición de las Filipinas aumentó exponencialmente la implicación estadounidense en el Pacífico, por si fuera poco, el ascenso de Estados Unidos se vio acompañado por el nipón, que desde el comienzo del periodo Meiji había emprendido un proceso modernizador que le llevaría a controlar gran parte del Pacífico e importantes áreas de Asia continental; de modo que T. Roosevelt además de percibir a Alemania como su rival más peligroso en el Caribe, veía en Japón una creciente amenaza para la estabilidad asiática, así que no dudó en animar a los empresarios estadounidenses para que invirtiesen en China y así aumentar la influencia nacional en dicho país, ni en mediar en la guerra ruso-japonesa de 1905 ante el temor de que cualquiera de los dos ganase demasiados territorios en el norte de China. Con la paz de Portsmouth se paralizaba el conflic-

51 ZIMMERMANN, op. cit., p. 3.

52 MORRIS, Theodore Rex, op. cit., p. 494.

53 BEALE, Theodore Roosevelt and the Rise of America to World Power, The Johns Hopkins University Press, Baltimore, 1987, p. 331.

54 «En mi opinión el servicio más importante que di a la paz fue el viaje de la Armada alrededor del mundo. Llegué a convencerme por numerosas razones lo esencial que era que tuviésemos claramente comprendido, por nuestro pueblo especialmente, pero también por otros pueblos, que el Pacífico era nuestro hogar tanto como el Atlántico, y que nuestra Armada podría y pasaría de uno a otro de los grandes océanos», ROOSEVELT, An autobiography, op. cit., cap. XV, párrafo 28.

55 Ibíd., Cáp. X, párrafo 52.

56 Ibíd., Cáp. XIV, párrafo 1. 
to con un Japón que salía del mismo reforzado como principal potencia asiática ${ }^{57}$, para T. Roosvelt apaciguar al dragón nipón fue su mayor logro en el segundo mandato presidencial, sin duda, el temor a un posible ataque japonés a las Filipinas o Hawai pesaban más que la amenaza del creciente poder nipón, al que se cedió sin restricciones la península coreana, y si bien Estados Unidos siempre intentó aparecer ante las autoridades chinas como su defensor ante el imperialismo del resto de potencias, el pragmatismo realista de Roosevelt le condujo a aceptar la primacía nipona en la región sin poner por ello en riesgo los intereses estadounidenses. Como veremos en el caso europeo, la prioridad en Asia para Roosevelt fue mantener el equilibrio de poder en la región, equilibrio que la lucha entre Rusia y Japón en China amenazaba con romper, no en vano, para el Presidente norteamericano el Pacífico sería lo que el Mediterráneo fue para la antigua Grecia, el nuevo centro mundial, y Estados Unidos no debía perder ese tren ${ }^{58}$, debido principalmente al deseo expansionista de poder y prestigio mundiales, con China como principal escenario, pero también por la teoría de esparcir la civilización, por ayudar a Gran Bretaña, necesitada de aliados en la región, y movido en parte por motivos económicos (con el objetivo de mantener el comercio abierto en China, incluso se creó en 1905 la Compañía Americana de Desarrollo de China, un consorcio para la obtención de contratos de construcción de vías férreas en China que, encabezado por J. P. Morgan, contaba con un fuerte apoyo de la Administración, para entonces las exportaciones a Japón y China ya doblaban las destinadas a Suramérica ${ }^{59}$ ). Por todo ello no sorprende que T. Roosevelt viese en Rusia al principal obstáculo a su política de Puertas Abiertas, buscando para contrarrestarla la colaboración de Londres, Berlín y Tokio, llegando incluso en 1903 a protestar por su política hacia los judíos con el fin de obligarle a abrir varios puertos en Manchuria y retirar de ellos las tropas allí estacionadas. Con todo ello, se aclara la participación de T. Roosevelt como mediador en la guerra ruso-japonesa, que amenazaba con convertir al vencedor de la misma en el hegemón asiático, desenlace totalmente contrario al equilibrio de poder buscado por la Administración Roosevelt.

- Europa: una de las constantes de la diplomacia estadounidense ha sido su aversión a verse enredada en los asuntos europeos, Roosevelt daría los primeros pasos en la eliminación de dicha restricción en 1906 al mediar en la disputa por Marruecos entre franceses y alemanes en la Conferencia de Algeciras, y tratar así de apaciguar el ardor imperial del Kaiser Guillermo Il; ese mismo año, también incluyó a Estados Unidos en la II Conferencia de la Haya para el establecimiento de un con-

57 ZIMMERMANN, op. cit., p. 470. En realidad, el éxito de T. Roosevelt en las negociaciones de paz ruso-japonesas se debió en gran medida a las calamitosas condiciones económicas de los contendientes, pues ninguno de los dos podía permitirse la reanudación del conflicto, de ahí que Japón renunciase a sus exorbitantes condiciones impuestas en un principio (como el pago ruso de una indemnización económica, el desarme de los puertos bajo control ruso, o la salida de Manchuria) y que Rusia cediese en la división de la isla Sakhalin, MORRIS, Theodore Rex, op. cit., p. 400-411.

${ }^{58}$ En lo relativo a China y al equilibrio de poder asiático consultar BEALE, ob.cit., p 172-251 y 253334.

59 MOWRY, op. cit., p. 181. 
junto de reglas de guerra, pues para T. Roosevelt si Estados Unidos era una gran nación debía estar presente en los foros de grandes potencias para así tratar de influirlos y acercarlos al ideal estadounidense de un sistema internacional gobernado por el respeto a la ley y el orden ${ }^{60}$; cabe destacar que durante todo el proceso de acercamiento a los asuntos europeos, Estados Unidos fue estrechando continuamente sus lazos con Gran Bretaña, plasmándose la solidaridad anglosajona en el acuerdo negociado por Hay con los representantes británicos acerca del trazado definitivo de la frontera con Canadá de 190361, Tratado Hay-Herbert, y que selló la unión anglosajona en el concierto internacional, acabando de paso con la rivalidad que les enfrentaba desde la guerra de Independencia, y colocando así a Alemania como principal rival a contener en Europa. El acercamiento a Gran Bretaña formó parte de una política plenamente consciente de T. Roosevelt encaminada a mantener el equilibrio de poder en Europa, concebido como el intento por evitar que cualquier nación fuera tan poderosa como para amenazar los derechos del resto de potencias, corriéndose el riesgo de una guerra mundial si no se mantenía dicho equilibrio ${ }^{62}$, por ello, para mantener ese precario equilibrio de poder europeo, T. Roosevelt participaría tanto en la Conferencia de la Haya de 1905 como en la de Algeciras un año más tarde. En Algeciras, al igual que sucediera en Portsmouth meses atrás, T. Roosevelt jugó con alemanes y franceses igual que lo había hecho con rusos y japoneses, intentando mantener en todo momento el precario equilibrio de poder que desde Tokio y Berlín comenzaba a cuestionarse. En el proceso, T. Roosevelt sufrió diversas críticas internas, como la del Senador Bacon, Demócrata por Georgia, por renunciar a la gran regla washingtoniana al dejarse enredar en los asuntos europeos, además, con la resistencia alemana a plegarse a los planes presidenciales, aumentaron las peticiones en el Congreso de abstenerse y retirarse de la conferencia, mientras Lodge trataba de defender la iniciativa presidencial como un intento por aumentar el peso moral de Estados Unidos en el mundo ${ }^{63}$. Tales esfuerzos encaminados a poner a Estados Unidos en el centro de la lucha por mantener el equilibrio de poder mundial eran fruto del papel protagónico que T. Roosevelt ansiaba para su país, más aún si Gran Bretaña perdía la condición de potencia líder, posición que enseguida tendría que cubrir Estados Unidos, según los planes de su Presidente. Todo ello dejó a Alemania como la potencia a contener en Europa.

- Caribe: para comprender la política hemisférica de T. Roosevelt antes hay que tener presente que para él la observancia y permanencia de la Doctrina Monroe era cardinal, ya que «no es ley internacional, pero sí un principio carpital de nuestra política exterior ${ }^{64}$. La guerra con España había convertido a la cuenca caribeña en un lago norteamericano, con las perspectivas de la construcción del canal interoceánico en el istmo de Panamá, los intereses geoestratégicos de Estados Unidos en

60 SCHULZINGER, U.S. diplomacy since 1900, Oxford University Press, New York, 2002, p. 36.

61 ZIMMERMANN, op. cit., p. 452.

${ }^{62}$ Para consultar lo relativo al mantenimiento del equilibrio de poder ver BEALE, ob.cit., p. 336-449.

${ }^{63}$ MOWRY, op. cit., p. 195.

64 ROOSEVELT, op. cit., cap. XIV, párrafo 7. 
la región sólo hicieron que aumentar, y una vez descartada Nicaragua como emplazamiento para el canal, se presionó a las autoridades colombianas para conceder a Estados Unidos el derecho a construirlo en su provincia panameña, tras el rechazo del Senado colombiano al proyecto, los separatistas panameños se alzaron con el apoyo estadounidense. Con la secesión, Estados Unidos logró el ansiado acuerdo de construcción del canal, firmado el 18 de noviembre por el Ministro Plenipotenciario en Washington Bunau-Varilla, antiguo representante de una de las compañías francesas que habían fracasado anteriormente en la construcción del canal, y que había ganado su cargo tras apoyar económicamente a los rebeldes panameños ${ }^{65}$. Con el nuevo acuerdo, Estados Unidos se comprometía a garantizar la seguridad de Panamá en contrapartida a las ventajas que se le concedían (control exclusivo del canal a perpetuidad y de una franja de $18 \mathrm{Km}$. alrededor del mismo, y cuya construcción no finalizó hasta 1914). Para Roosevelt éste fue el mayor logro diplomático de su primer mandato, para él, la construcción del canal era del «interés de la civilización colectiva. Si alguna vez un Gobierno ha podido decir que ha recibido un mandato de la civilización...los Estados Unidos guardan esa posición respecto al canal interoceánico» ${ }^{66}$, es decir, para Roosevelt su Gobierno había actuado no sólo en interés de la nación, sino del bien mundial, pues nadie se podía permitir un nuevo retraso en la construcción del canal. Con respecto al resto de Latinoamérica, la Administración de T. Roosevelt no permaneció al margen de la amenaza siempre presente de la intervención europea en los asuntos continentales a causa de las deudas estatales, así, en 1902 Venezuela, como décadas atrás México, se vio amenazada por varias potencias europeas por el impago de sus deudas, y tras el bloqueo de su puertos, T. Roosevelt instó al Gobierno venezolano y al alemán para que resolvieran sus diferencias ante el tribunal de La Haya. A causa de Venezuela, o mejor dicho, por la defensa de la Doctrina Monroe, T. Roosevelt estuvo dispuesto incluso a llegar a la guerra con Alemania67. No es extraño pues, que tras el bloqueo naval impuesto por los europeos a Venezuela, Roosevelt proclamara su corolario a la Doctrina Monroe:

«Todo lo que este país desea es ver a los países vecinos estables, ordenados y prósperos. Todo país cuya gente se conduzca bien puede contar con nuestra amistad. Si una nación muestra que sabe actuar con razonable eficiencia y decencia en asuntos políticos y sociales, si mantiene el orden y paga sus obligaciones, no necesita temer la intervención de Estados Unidos. La incompetencia crónica o una impotencia que resulten en una pérdida general de los lazos de la sociedad civilizada, puede en América, y en cualquier otro lugar, requerir en último término la intervención de alguna nación civilizada, y en el hemisferio occidental la adherencia de los Estados Unidos a la Doctrina Monroe debe forzar a los Estados Unidos, aunque de forma reluctante, en casos flagrantes de incompetencia o impotencia, al ejercicio de un poder de policía internacional» 68

65 MORRIS, Theodore Rex, op. cit., p. 279.

66 ZIMMERMANN, op. cit., p. 434.

67 MORRIS, Theodore Rex, op. cit., p. 187.

68 Consultado en www.theodoresroosevelt.org 
No en vano, T. Roosevelt consideraba que «la Doctrina Monroe debe ser el rasgo cardinal de la política exterior de todas las naciones de las dos Américas» ${ }^{69}$, al considerarla como «una declaración de que no debe haber engrandecimiento territorial por ninguna potencia no americana a expensas de ninguna potencia americana en suelo americano ${ }^{70}$. Con su corolario a la Doctrina Monroe, Roosevelt transformaba ésta, pues de ser una prohibición a los países europeos de inmiscuirse en los asuntos americanos, se convirtió en una justificación de la intervención estadounidense en toda Latinoamérica, es decir, en una expansión continental de la enmienda Platt y del derecho de injerencia estadounidense en los asuntos internos de los países de la región. Para T. Roosevelt, que Estados Unidos se hiciese cargo del desgobierno regional era una consecuencia lógica de sus prejuicios sobre la superioridad de la civilización norteamericana, además, con ello se intentaba desterrar de una vez por todas la amenaza de que Alemania se hiciese con algún punto clave en la región como consecuencia del impago de deudas. Su corolario lo tradujo en la práctica con su famosa frase «habla con suavidad y porta un gran garrote» ${ }^{71}$, para 1904, año en que fue reelegido con una abrumadora mayoría de votos (y primera vez que un Presidente «accidental» era reelegido para la presidencia), Roosevelt tenía ya diseñadas las bases del intervencionismo continental estadounidense al ligar inextricablemente los intereses económicos de Estados Unidos con sus objetivos geoestratégicos ${ }^{72}$, así, en Honduras, donde los empresarios estadounidenses poseían la mayoría de las minas y controlaban la mayor exportación del país, la banana, Estados Unidos comenzó en 1903 una serie de intervenciones directas para controlar a los Gobiernos hondureños que mantenían un conflicto fronterizo con Nicaragua y vivían una situación de inestabilidad crónica; también en la República Dominicana Roosevelt aplicaría su corolario, si en 1905 se firmó un acuerdo por el que Estados Unidos se hacía cargo de sus finanzas, dos años más tarde comenzó el control directo de las aduanas, con el que el $45 \%$ de lo recaudado iba a las arcas dominicanas y el $55 \%$ restante a un fondo neoyorquino para el pago de la deuda, y una ocupación armada que no acabaría con la inestabilidad interna del país (el acuerdo aduanero perduraría hasta 1940), para el propio presidente Roosevelt la inestabilidad interna de los países caribeños, más que el intervencionismo europeo, era lo que impulsaba a Estados Unidos a actuar en la región73; también Cuba sufriría los embates del "gran garrote» estadounidense, y tras la retirada de sus soldados en 1902, estos volverían cuatro años más tarde ante la revuelta desencadenada como protesta por la reelección del pro estadounidense Estrada Palma, estableciendo una administración temporal hasta el restablecimiento del orden y la celebración de nuevas elecciones ${ }^{74}$.

\footnotetext{
69 ROOSEVELT, Theodore, primer discurso anual del 3 de diciembre de 1901, texto consultado en www.psresidency.ucsb.edu/ws/index.php?pid=29542

70 lbíd.

71 www.whitehouse.gov/history/presidents/tr26.html

72 SCHULZINGER, op. cit., p. 31.

73 ROOSEVELT, An Autobiography, op. cit., cap. XIV, párrafo 14.

${ }^{74}$ MORRIS, Theodore Rex, op. cit., p. 461.
} 
De las políticas aplicadas por Roosevelt y su equipo en las diferentes áreas de interés se pueden extraer las notas principales de su conservadurismo internacional, para Zimmermann ${ }^{75}$ éstas podrían resumirse en la necesidad de obtener un imperio colonial con el que reforzar la posición mundial de Estados Unidos, en el cual la obtención de una serie de bases, al modo británico, era esencial para los intereses estadounidenses; lo que representaba una novedad en la historia de Estados Unidos, pues nunca antes se habían asegurado los intereses nacionales fuera del territorio continental, algo que a partir de entonces sería crucial para el ascenso nacional al status de superpotencia; dicha promoción internacional se haría bajo dos prioridades fundamentales en las relaciones exteriores como son el respeto a los derechos humanos y la búsqueda de la estabilidad mundial, por último, la Administración de T. Roosevelt supuso el refuerzo definitivo del Ejecutivo respecto al Congreso, que había dominado la política nacional desde el final de la guerra civil, un proceso que se había iniciado con Cleveland y McKinley pero que la personalidad de T. Roosevelt apuntaló vigorosamente para convertir al Presidente de la nación en el motor del impulso político estadounidense.

Con una mezcla de realismo hamiltoniano aderezado con la importancia concedida a los aspectos económico-comerciales de la política exterior nacional y de un populismo jacksoniano salpicado en ocasiones por un nacionalismo y una política de fuerza poco sofisticados, la Administración de T. Roosevelt supo apartar a la diplomacia estadounidense de sus comienzos unilateralistas y dotarla así de un nuevo carácter intervencionista en los asuntos mundiales. El internacionalismo conservador fue el primer intento de reorientación estratégica emprendido en Estados Unidos, hasta el momento, los líderes de la nación se habían contentado con finalizar la conquista continental y curar las heridas de la Guerra Civil, pero con la adquisición del imperio de ultramar y la voluntad de una nueva generación de políticos, Estados Unidos adquirió un nuevo status de potencia mundial que la alejaba definitivamente de los sueños jeffersonianos de una pequeña república cuya revolución había triunfado, muy al contrario, surgía un gigante en plena expansión con el firme propósito de continuar con la misión de propagar su modelo allá donde se encaminase. Que al hacerlo se viera impelido a usar el gastado lenguaje de las viejas potencias europeas, con sus queridos balance de poder, interés nacional, esferas de influencia y geoestrategia, era sólo parte del precio que Estados Unidos debía pagar en su tránsito de primera nación descolonizada a potencia mundial.

\section{EL GRAN DEBATE EN TORNO A LA SOCIEDAD DE NACIONES}

El Internacionalismo conservador legado por T. Roosevelt al Partido Republicano no triunfó en última instancia debido a los esfuerzos que imponía sobre la nación para su implementación, sobre todo en materia de defensa, y que chocaban

\footnotetext{
75 ROOSEVELT, op. cit., cap. XIV p. 493.
} 
frontalmente con la inercia unilateralista y aislacionista de más de un siglo de existencia. Su sucesor en la Casa Blanca, W. H. Taft, no dudó en basar su internacionalismo en el interés económico, elevando la diplomacia del dólar a política oficial de Washington. Aún con todo, con W. Wilson ya en la presidencia, las notas principales del Internacionalismo conservador fueron asumidas por el Partido Republicano a la hora de oponerse a la paz diseñada por Wilson en París, y que en la práctica implicaba la participación activa de Estados Unidos en una estructura permanente de seguridad internacional, lo que conferiría un nuevo impulso al internacionalismo estadounidense de la mano de las tesis liberal democráticas impuestas por W. Wilson.

La lucha por la Sociedad, como se dio a conocer el debate que dividió al Congreso estadounidense a la hora de ratificar el Tratado de paz de Versalles que el propio Wilson ataría a la aprobación de su Sociedad de Naciones, fue el escenario donde los internacionalismos conservador y liberal democrático midieron sus fuerzas, con el objetivo de controlar la política exterior de Estados Unidos. Más que una división partidista, con el Partido Republicano defendiendo el internacionalismo conservador y el Demócrata el liberal democrático, lo que se produjo fue el conflicto entre, por un lado, dos concepciones distintas del internacionalismo, y por otro, entre los residuos del unilateralismo aislacionista y el internacionalismo dominante ya entonces. De ahí la importancia del debate en torno a la Sociedad de Naciones, tanto para explicar la evolución del pensamiento de T. Roosevelt, como el desarrollo histórico de los Estados Unidos de entreguerras.

Durante 1919 y 1920 la entrada de Estados Unidos en la Sociedad se convirtió en la cuestión política más importante y debatida desde la Guerra Civil, y todo pese al acuerdo existente entre ambos Partidos sobre grandes áreas del Tratado y al virtual consenso sobre la mayoría de los supuestos y valores que lo impregnaban. Así, para Cooper, los sentimientos que prevalecían entre los contendientes se pueden resumir en una fe ciega en el carácter único de unos Estados Unidos virtuosos y democráticos, a lo que habría de sumar el respeto a ciertos intereses nacionales (de seguridad, prosperidad y soberanía), es decir, la esencia del debate recaía en la reconciliación entre la participación y el compromiso internacionales por un lado y el respeto a la soberanía nacional por otro, con un trasfondo por el control de la política exterior estadounidense (quién la conduce y cómo) desglosado en tres dimensiones, a saber, la formal/constitucional, la partidista y la estratégico-ideológica, de tal forma que a la postre los aspectos de política mundial se supeditaron a lo relativo a la política exterior estadounidense ${ }^{76}$.

En la campaña presidencial de 1916 el candidato Republicano C. E. Hughes se postuló a favor de una organización internacional, lo que da idea del consenso que sobre la materia existía ya antes de que Estados Unidos entrase en la I Guerra

${ }^{76}$ COOPER, J. M. Breaking the Heart of the World. Woodrow Wilson and the Fight for the League of Nations, Cambrigde University Press, Cambridge, 2001, p. I, 4-5. 
Mundial, en todo caso la reelección de W. Wilson supuso un aumento de los esfuerzos de éste por acabar con el conflicto a través de un acuerdo que creara las condiciones para un nuevo orden internacional, con la entrada estadounidense en el mismo como incentivo para que los contendientes cesasen las hostilidades, lo que le valió duras críticas internas por intentar mezclar a Estados Unidos en los asuntos europeos ${ }^{77}$. De cualquier forma, el Internacionalismo liberal democrático de W. Wilson rompía el consenso bipartidista sobre la materia pues lo que Wilson tenía en mente, más que involucrar a Estados Unidos en Europa con el fin de acabar con más guerras mundiales, era americanizar el sistema político internacional, como el propio Presidente dejara muy claro en su discurso del 22 de enero de 1917 ante el Senado:

«Estoy proponiendo, tal como es, que las naciones deberían a través de un acuerdo adoptar la doctrina del Presidente Monroe como la doctrina del mundo: que ninguna nación debe buscar extender su política sobre ninguna otra nación o pueblo, y sí que todo pueblo debe ser dejado libre para determinar su propia política, su propio modo de desarrollo, sin restricciones, sin ser amenazado, sin miedo, los pequeños como los más poderosos.

Estoy proponiendo que todas las naciones desde ahora prohíban las alianzas cerradas que les conducirán a competiciones de poder, atrapándoles en una red de intriga y rivalidad egoísta, deformando sus propios asuntos por las influencias introducidas desde fuera.

Estos son principios americanos, políticas americanas [...] Son los principios de la humanidad y deben prevalecer» 78

Dentro del Partido Republicano existían diversas corrientes de oposición al programa del Presidente Wilson, así, la Sociedad para Reforzar la Paz se encontraba en el extremo más internacionalista del Partido Republicano, al otro se encontraba el formado por los contrarios a la participación de Estados Unidos en cualquier organización internacional, tildados de aislacionistas, y en medio la mayoría del Partido que sí aceptaba la entrada en la misma pero con condiciones, como era el caso de H. C. Lodge, E. Root o P. C. Knox, si bien éste último recalaría en las filas de los Irreconciliables rechazando totalmente la entrada en la Sociedad de Naciones, mientras que para T. Roosevelt, quien hasta su muerte en enero de 1919 sonaba como posible candidato Republicano, una Sociedad de Naciones no era necesaria, bastando con que las naciones civilizadas impusieran el orden gracias a una labor policial mundial, una clara reminiscencia de la política de grandes naciones imperante durante sus días en la presidencia ${ }^{79}$.

En el fondo de la discusión se encontraban las distintas conclusiones que del conflicto sacaron los protagonistas del debate, si Wilson entendió la I Guerra

\footnotetext{
77 Ibíd., p. 18.

78 WILSON. W., discurso del 22 de enero de 1917 ante el Senado, consultado íntegro en http://wwl2.dataformat.com/Document.aspx?doc=30688

79 COOPER, op. cit., p. 28. y 39-42.
} 
Mundial como un maremoto histórico que cambió por completo al mundo, Lodge consideraba que la guerra no había dejado inservibles los mecanismos de la diplomacia tradicional, y por lo tanto defendía una visión más regionalista que globalista, optando por conservar la unión con los aliados como mejor modo de conservar la paz mundial antes que hacer recaer su defensa en un organismo internacional, con ello coincidía con su compañero de Partido Knox, antiguo Fiscal General con T. Roosevelt y Secretario de Estado con Taft, quien además abogaba por reforzar el arbitrio internacional gracias a una corte mundial en el seno de la Sociedad de Naciones ${ }^{80}$. En medio se encontraban Taft y sus seguidores, quienes eran partidarios de la Sociedad de Naciones pero también eran conscientes de la necesidad de mantener la unidad del Partido Republicano.

Más radicales en sus reivindicaciones respecto a la Sociedad de Naciones eran los integrantes de la Sociedad para la Preservación de la Independencia Americana, liderada por el ex Senador Beveridge y los Senadores G. H. Moses y H. W. Jonson, quienes sólo aceptaban la entrada estadounidense en la Sociedad si se separaba del Tratado de Paz, se reconocía el derecho a retirarse de la misma, no violaba la Doctrina Monroe ni interfería en los asuntos internos ni obligaba a la nación a luchar en cuestiones lejanas ${ }^{81}$. Con todo, el sentimiento antiinternacionalista no era patrimonio exclusivo Republicano, también los Demócratas contaban con un ala aislacionista formada principalmente por Representantes agrarios como J. K. Vardaman de Misissippi o T. Hardwick de Georgia, por si fuera poco para Wilson, los duros términos finales impuestos a Alemania en la paz le restaron el apoyo del sector más liberal de su propio Partido, contrario a lo que consideraron una paz injusta en contradicción con el mensaje de su Presidente ${ }^{82}$.

De modo que a inicios de marzo de 1919, cuando dio comienzo el debate de ratificación del Tratado de Paz en el Senado, ya se habían aclarado las distintas posturas sobre el mismo, pudiéndose distinguir tres como las más importantes:

1. Los partidarios del Tratado y de la entrada de Estados Unidos en la Sociedad de Naciones, en su amplia mayoría Demócratas, sobre unos cuarenta Senadores,

2. Los partidarios de la entrada de Estados Unidos en la Sociedad pero con reservas, en su mayoría Republicanos, también alrededor de cuarenta Senadores y

3. Los que se negaban a la entrada de Estados Unidos en la Sociedad, en su mayoría Republicanos pero también con una minoría Demócrata, en torno a la docena.

80 lbid., p. 65.

81 lbid., p. 80.

82 AMBROSIUS, L. Wilsonianism. Woodrow Wilson and his legacy in American foreign relations, Palgrave Macmillan, 2002, p. 120. 
Por tanto, para la mayoría del Republicanismo su objetivo se basaba en atenuar el Internacionalismo liberal democrático de la Administración Wilson, y así lograr que el Internacionalismo conservador continuara influyendo en la política exterior de Estados Unidos. Para Knox no se trataba tanto de aislar a Estados Unidos de los asuntos mundiales como de rechazar el modelo presentado por el Presidente Wilson, incluso llegó a postular una doctrina que compensase el rechazo de la entrada en la Sociedad de Naciones considerando cualquier crisis en Europa como un asunto esencial para la seguridad estadounidense, y estudiando el mejor modo de resolverla pero sin alianzas, teniendo en ello siempre presente la regla washingoniana contra las alianzas permanentes. Incluso ésta doctrina era una concesión demasiado internacionalista para el resto de Irreconciliables, todo lo contrario que para la mayoría del Partido, unido gracias a Lodge en torno al programa de reservas al plan del Presidente Wilson diseñado por E. Root, quien aspiraba a salvar la ratificación de la Sociedad de Naciones limitando su alcance a través del poder de retirada sin trabas tras dos años en la misma, negando el consentimiento al art. $10^{83}$ y reforzando la figura del arbitrio internacional como solución a los conflictos mundiales y asegurando que la entrada en la Sociedad no implicaría la renuncia a las políticas tradicionales de Estados Unidos, como la Doctrina Monroe $^{84}$.

Las reservas, elaboradas en su mayor parte por Elihu Root, que finalmente se presentaron para acompañar el Tratado de Versalles, una vez rechazado éste por el Senado, ascendían a 15, siendo:

1. Estados Unidos sería el único juez para decidir su permanencia en la Sociedad de Naciones, previo acuerdo de su Congreso,

2. «El Congreso de Estados Unidos no asume ninguna obligación de preservar la integridad territorial o la independencia política de otro país, con el empleo de sus fuerzas navales o militares, sus recursos o cualquier forma de discriminación económica...bajo las provisiones del artículo 10...si en cualquier caso particular el Congreso, quien bajo la Constitución, tiene el único poder de declarar la guerra o autorizar el empleo de fuerzas navales y militares, lo prevé, en el ejercicio de sus plena libertad de acción ${ }^{85}$,

3. «Ningún mandato será aceptado por Estados Unidos bajo el artículo 22... salvo por la acción del Congreso de Estados Unidos»86,

83 Por el art. 10 del Pacto de la Sociedad de Naciones los miembros de la misma asumían «respetar y preservar contra la agresión externa a la integridad territorial y la independencia política existente de todos los miembros de la Sociedad. En caso de que dicha agresión o en caso de amenaza o peligro de tal agresión, el Consejo deberá sugerir los medios por los cuales tal obligación sea satisfecha». El art. 10 venía a ser completado por el art. 16 según el cual todo agresor sobre cualquiera de los miembros de la Sociedad «será ipso facto considerado como culpable de un acto de guerra contra todos los miembros de la Sociedad de Naciones». Pacto consultado en http://avalon.law.yale.edu/20th century/leagcov.asp

${ }^{84}$ COOPER, op. cit., p.100-107.

85 Resolución de ratificación del Senado, texto consultado en http://poa1.uned.es/web/ehost

86 Ibíd. 
4. Todos los asuntos internos de Estados Unidos están bajo su exclusiva jurisdicción, no siendo susceptibles de someterse a la Sociedad de Naciones ni a recomendaciones de otros países,

5. Estados Unidos no someterá a arbitraje ni a la Sociedad de Naciones cuestiones relativas a la Doctrina Monroe, por ser, al igual que el campo doméstico, de su entera jurisdicción,

6. «Estados Unidos niega su consentimiento a los artículos 156, 157 y 158»87, relativos a la cesión de territorios alemanes a Japón,

7. Todo ciudadano estadounidense nombrado para servir en la Sociedad de Naciones debe recibir previamente al visto bueno del Congreso de Estados Unidos,

8. El Congreso estadounidense aprobará las interferencias de la Sociedad de Naciones con el comercio con Alemania,

9. El Congreso estadounidense aprobará las sumas destinadas al presupuesto de la Sociedad de Naciones,

10. «Ningún plan de limitación de armamentos propuesto por el consejo de la Sociedad de Naciones bajo las provisiones del artículo 8 serán consideradas vinculantes por Estados Unidos hasta que el mismo no sea aceptado por el Congreso ${ }^{88}$,

11. Estados Unidos se reserva la facultad de comerciar con nacionales de países que hayan roto con el convenio de la Sociedad de Naciones,

12. Ninguna disposición sobre deudas y propiedades del Tratado de Versalles podrá vulnerar los derechos de los ciudadanos estadounidenses,

13. Estados Unidos no se verá obligado en lo relativo a la Organización del Trabajo hasta no ratificar sus artículos y reservas,

14. Estados Unidos no aprobará su participación en la Sociedad de Naciones hasta no ver asegurada la igualdad de votos en la misma,

15. Al ratificar el Tratado, Estados Unidos se adhiere también a la libre autodeterminación de Irlanda y espera su pronta integración como un miembro más en la Sociedad de Naciones.

Como se puede apreciar, las enmiendas trataban de preservar la independencia y soberanía nacionales ante el temor de ver ambas cercenadas con la participación de Estados Unidos en la Sociedad de Naciones, y en ningún caso representaban una negativa total a dicha organización, salvo en lo relativo a los mandatos que no estaban dispuestos a aceptar. De hecho los Republicanos internacionalistas como Root 
y Lodge aprobarían la mayoría de los contenidos del convenio siempre que no menoscabasen los poderes reservados al Congreso por la Constitución estadounidense, verdadero centro de la polémica entre presidencia y Senado, pues temían que con la Sociedad, lo que de verdad intentaba Wilson era que el Ejecutivo sobrepasase la potestad del Legislativo respecto a la definición de la política exterior de la nación, dañando así los equilibrios de poderes internos, y cuyas reservas, como acabamos de ver, trataban de impedir. En resumen, mientras para Root, Lodge y resto de Republicanos moderados, las enmiendas al convenio de la Sociedad de Naciones eran esenciales al garantizar con ello el régimen democrático y republicano sancionado en la Constitución estadounidense, para Wilson la aprobación de su plan tal cual lo había presentado al Senado, era el único modo con el que contaba Estados Unidos para democratizar el sistema internacional y acabar así con el viejo orden europeo de diplomacia secreta y políticas de poder, verdadera amenaza existencial a ese mismo proyecto republicano y democrático. Asistimos pues con el debate sobre la Sociedad de Naciones a la tensión entre los internacionalismos conservador y liberal democrático, y sus distintas visiones sobre la promoción de la democracia, mientras el primero se centraba en conservar la soberanía nacional, el segundo lo hacía en promover un cambio en las pautas de comportamiento interestatal, un verdadero proyecto global que indefectiblemente habría de chocar con los temores a una corrupción del sistema democrático nacional de los Republicanos. Para los seguidores del Presidente Wilson, aprobar el tratado con las reservas Republicanas significaría de hecho su rechazo, además tales reservas apenas podían disimular el menosprecio Republicano por el Presidente y la falta de confianza en los aliados de Estados Unidos en la guerra.

El principal escollo a superar para Wilson fue la negativa de la oposición a aceptar el nuevo papel que pretendía para Estados Unidos en el nuevo entramado internacional diseñado por él mismo, pues los Republicanos no estaban dispuestos a aceptar que Estados Unidos se convirtiese en el «policía mundial» y verse así obligados a participar en numerosos conflictos alejados de sus intereses tradicionales; en particular, los republicanos temían que el artículo 10 implicase en la práctica una cláusula de asistencia militar inmediata en caso de agresión a cualquier miembro de la Sociedad de Naciones, lo que habría acabado con su estrategia tradicional de no sobrepasar los límites del hemisferio occidental. Wilson intentó salvar dichas reservas al art. 10, piedra angular de la Sociedad de Naciones, argumentando que sólo entrañaba una condena moral, y no una obligación legal, siendo más bien de carácter asesor, desde luego una interpretación muy alejada de la realizada por sus aliados, más aun en el caso francés. Ante la persistencia presidencial de no ceder en el asunto de la pertenencia, y liderazgo, estadounidense a la Sociedad, los Republicanos estuvieron dispuestos a desligar ésta del Tratado mismo de paz con tal de salvar aquel,

89 COOPER, op. cit., p. 141. 
pero para Wilson la Sociedad era indisociable y parte principal de los términos de paz, primordial para su defensa, de modo que tampoco cedió en este asunto ${ }^{89}$.

Por tanto, el rechazo Republicano al programa del Presidente Wilson y su insistencia en enmendarlo, respondía a diferencias irreconciliables tanto en el plano formal/constitucional, al ver los Republicanos en la Sociedad de Naciones la vía más segura para una perversión de los equilibrios y balances incorporados en la constitución estadounidense, y que en última instancia amenazaban con subvertir el sistema democrático y republicano nacido de la Independencia; como en el plano ideológico/estratégico, pues para los Republicanos, lejos de tratar de convertir al resto de potencias y al sistema internacional en su conjunto, en un remedo del sistema político estadounidense, Estados Unidos debía preservar primero sus intereses y alejarse de cualquier ilusión mesiánica, pues con ello sólo se vería enredado en problemas ajenos muy alejados de sus verdaderos intereses nacionales, no en vano, aunque la mayoría del Partido Republicano apoyara la participación en cierto tipo de organización internacional, su defensa a ultranza de la soberanía nacional les obligaba a limitar el carácter de dicha participación.

El drama concluiría con el rechazo del Senado a la ratificación del Tratado de Versalles, tanto en la votación del 19 de noviembre de 1919 como en la del 19 de marzo de 1920, con o sin reservas, con un Presidente inválido y cada vez más alejado del favor tanto de la clase política como de la opinión pública. Como se aprecia, el peso del rechazo de la Sociedad habría que repartirlo a partes iguales entre Republicanos y Presidente, pues ambos bandos rechazaron por igual los proyectos de sus rivales, 39 votos a favor por 55 en contra para el proyecto con enmiendas y 38 favor y 53 en contra para el plan sin ellas, que de haberse aprobado cualquiera de los dos hubiese supuesto la entrada de Estados Unidos en la misma ${ }^{90}$. En marzo de 1920 un débil Wilson tuvo que aceptar la votación del Tratado con reservas, con 35 votos en contra y 49 a favor, a los partidarios del tratado con enmiendas les separaron sólo siete votos de una victoria histórica ${ }^{91}$.

Tras el rechazo al Tratado y a la entrada en la Sociedad, el Partido Republicano se hizo con la iniciativa en materia de política exterior, aprobándose en el Congreso varias resoluciones auspiciadas por él, como las relativas a firmar la paz por separado con Alemania a finales de abril, la vetada por Wilson a fines de mayo y presentada por Knox para organizar una nueva conferencia internacional según las líneas de su programa (corte mundial, arbitrio internacional, prohibición de la guerra...) y en junio el Congreso vetaría la iniciativa presidencial de aceptar el mandato sobre Armenia ${ }^{92}$.

${ }^{90}$ www.senate.gov/reference/reference item/Versailles.htm

${ }^{91}$ www.u-s-history.com/pages/h1338.html

92 COOPER, op. cit., p. 378. 


\section{EL INTERNACIONALISMO DE T. ROOSEVELT FRENTE AL INTERNACIONALISMO REPUBLICANO}

Una vez lejos de la Casa Blanca, a partir de $1911 \mathrm{~T}$. Roosevelt fue asumiendo su error a la hora de elegir a W. H. Taft como su sucesor, y aunque el grueso de su distanciamiento se debiera a cuestiones domésticas en torno al presunto alejamiento de Taft del programa progresivista y su acercamiento a los postulados de la maquinaria del Partido y el gran capital, no fue menos importante el creciente desacuerdo que sobre política exterior se iba fraguando entre el Republicanismo regular y su anterior jefe de filas.

W. H. Taft continuó con la insistencia de la Administración Roosevelt en la resolución pacífica de las controversias internacionales a través del arbitrio, no en vano era presidente honorario de la Sociedad Americana para el Arreglo Judicial de las Disputas Internacionales, mientras que T. Roosevelt había evolucionado su postura hacia la defensa de un tribunal internacional con poder punitivo, e incluso rechazaba los tratados de arbitrio bilaterales patrocinados por la Administración Taft, salvo con Gran Bretaña, al considerar que ponían en cuestión el honor, la independencia e integridad de Estados Unidos, es más, T. Roosevelt aspiraba a que Washington sustituyese a Londres como reforzador de la paz mundial, sin ignorar, como temía que estaba haciendo Taft, los conflictos que se estaba gestando en Europa Central y que ningún arbitrio podría resolver ${ }^{93}$. Para T. Roosevelt «aunque el romper un tratado es condenable, sería mucho más temerario hacer un tratado que no podemos mantener ${ }^{94}$ pues «ningún bien ha venido de tratados que representan una farsa; y bajo las condiciones actuales es hipócrita para una nación anunciar que arbitrará cuestiones de honor e interés vitales, y una locura pensar que los oponentes acatarán dichos tratados» ${ }^{95}$. Ya que

«el punto que deseo destacar es, primero, la extrema necedad e irregularidad de hacer promesas que no podemos mantener, $y$, segundo, la absoluta futilidad de esperar que en cualquier caso excepcional una potencia fuerte mantenga una promesa que considera va en su contra, a no ser que haya alguna forma de respaldar con la fuerza la demanda de que el tratado sea respetado»96

De hecho, para T. Roosevelt las convenciones de La Haya de 1899 y 1907, el mayor esfuerzo internacional hasta la fecha en materia de paz y seguridad inter-

\footnotetext{
93 MORRIS, E. Colonel Roosevelt, Random House, New York, 2010, p. 10 y 137. Según el propio T. Roosevelt «concluimos con Gran Bretaña, y con gran parte de las otras naciones, tratados de arbitraje específicamente acordando arbitrar todos los asuntos, y especialmente la interpretación de los tratados, salvo las cuestiones relativas que afecten a la integridad nacional, el honor nacional y los intereses nacionales vitales», ROOSEVELT, T. «The Peace of Righteousness», artículo publicado en Outlook el 9 de septiembre de 1911, texto consultado en www.theodore-roosevelt.com.

94 ROOSEVELT, T. «Unwise Peace Treaties a Menace to Righteounness», America and the World War, Charles Scribner s Sons, New York, 1915, p. 45.

95 Ibíd., p. 47.

96 Ibíd., p. 47.
} 
nacional, «han probado ser inútiles, y siempre lo harán, si no hay sanción de fuerza detrás de ellos»97. Para el antiguo rough rider era digno de lamentarse el hecho de que «las naciones civilizadas no hayan diseñado un método por el cual el poder colectivo de la civilización pueda ser usado para prevenir o castigar tales crímenes (en referencia a la invasión alemana de Bélgica)»98.

La nueva crisis surgida en Marruecos era prueba suficiente para T. Roosevelt de la futilidad del mantenimiento de la paz judicial, y con ello de la política exterior de la Administración Taft, pues las grandes potencias sólo ansiaban dominar, y sólo cejarían en su lucha ante una fuerza mayor ${ }^{99}$, para T. Roosevelt

«hasta que la gente tenga firme en sus mentes que la paz es el valor principalmente como una media de rectitud, y que sólo puede ser considerada como un fin cuando también coincide con la rectitud, sólo podremos hacer un pequeño aporte al avance de su llegada a ésta tierra [...] en el presente no hay una fuerza internacional a la que acudir, y aún no veo cómo puede ser creada en el presente. Hasta ahora la paz ha llegado a menudo porque alguna potencia fuerte y en conjunto justa ha impuesto por la fuerza armada, o por la amenaza de la fuerza armada, fin al desorden» 100

Pero tal resultado sólo servía para instalar un determinado equilibrio de poder temporal, no servía a la causa de la paz mundial, de igual forma que tampoco servían los acuerdos internacionales sin respaldo de fuerza alguna, de modo que en opinión de T. Roosevelt «lo que se necesita en materias internacionales es crear un juez y después colocar una fuerza policial detrás de ese juez [...] lo esencial es liberar a cada nación del temor recurrente a su vecino»101, y ya que ni el desarme ni los tratados sin fuerza que los respalden han sido nunca la solución a los conflictos internacionales, «el único movimiento permanente para obtener la paz (...) es un acuerdo entre las grandes potencias, en el cual cada una se comprometa a cumplir las decisiones de un tribunal común sino también a respaldar con la fuerza las decisiones de tal tribunal» ${ }^{102}$, acuerdo que T. Roosevelt había denominado World League for the Peace of Righteounsness. El objetivo principal de T. Roosevelt era minimizar las oportunidades para que las guerras estallasen, y limitar y regular los conflictos una vez se desencadenasen, haciendo de la fuerza un agente de la justicia «en un esfuerzo por colocar la fortaleza de la humanidad civilizada detrás del propósito colectivo de asegurar la paz de la rectitud, la paz de la justicia entre las naciones de la tierra»103.

97 Ibíd., p. 54.

98 Ibíd., p. 55.

99 MORRIS, E. Colonel Roosevelt, op. cit. p. 145.

100 ROOSEVELT, T. «The Peace of Righteousness», artículo publicado en Outlook el 9 de septiembre de 1911, texto consultado en www.theodore-roosevelt.com.

101 ROOSEVELT, T. «How to Strive for World Peace», America and the World War, Charles Scribner s Sons, New York, 1915, p. 78.

102 Ibíd., p. 80.

103 Ibíd., p. 83. 
Con la llegada de W. Wilson a la presidencia tras la división del Partido Republicano debido a la intransigencia de T. Roosevelt, quien se presentó a las elecciones de 1912 bajo su propio Partido Progresivista, T. Roosevelt apoyó la neutralidad estadounidense al comienzo del conflicto en Europa, aunque sin dejar de presionar a favor de un aumento de la preparación militar de Estados Unidos $^{104}$, pero con el paso de los meses y el enquistamiento del conflicto, T. Roosevelt consideraba que la neutralidad iba en contra del interés nacional y de las obligaciones estadounidenses respecto a la humanidad ${ }^{105}$, contravenidas por la actitud de la Administración Wilson y su pasividad ante la injusticia cometida en la invasión de Bélgica, contraria a las convenciones de La Haya firmadas por Estados Unidos, y que para T. Roosevelt justificaba en sí misma cualquier acción que el Ejecutivo estadounidense considerase oportuna para hacer cumplir los tratados, "en otras palabras, debemos mostrar que creemos en el derecho y que por tanto cumplimos nuestras promesas de buena fe, y, más aun, que también podemos y estamos dispuestos a poner la fuerza detrás del derecho ${ }^{106}$.

En la raíz del plan de T. Roosevelt se encontraba su internacionalismo, pues él mismo ansiaba «que nos convirtamos en uno de los garantes conjuntos de la paz mundial» ${ }^{107}$, es decir, Estados Unidos debía ser una de las grandes potencias destinadas a convertirse en la policía mundial que hiciera cumplir las decisiones de ese tribunal mundial por él diseñado:

«en esencia este plan significa que deberá haber un gran tratado internacional para la paz de la justicia; que este tratado debe explícitamente asegurar a cada nación, salvo en lo relativo a las operaciones de cualquier tribunal internacional, tales materias como su integridad territorial, su honor, y sus intereses vitales; que este tratado debe por sus propios términos tomar precauciones a la hora de hacer promesas locas que no puedan ser mantenidas; que este tratado debe ser cumplido con absoluta buena fe (...) finalmente, y más importante, este tratado debe poner la fuerza detrás de la justicia, debe crear un método para asegurar, mediante el ejercicio de la fuerza, el cumplimiento de las solemnes obligaciones internacionales $\gg 108$

Y su carácter le llevaba a afirmar, en contra de la actitud pasiva de la Administración Wilson, que «ningún trabajo por la paz será nunca digno a no ser que venga acompañado de coraje, esfuerzo y sacrificio personal» ${ }^{109}$, y que «sólo las potencias civilizadas que poseen hombría viril de carácter y voluntad de aceptar el

104 MORRIS, E. Colonel Roosevelt, op. cit., p. 383.

105 ROOSEVELT, T. «An International Posse Comitatus», America and the World War, Charles Scribner s Sons, New York, 1915, p. 109.

106 Ibíd., p. 116.

107 Ibíd., p. 123.

108 ROOSEVELT, T «Utopia or Hell?», America and the World War, Charles Scribner s Sons, New York, 1915, p. 222.

109 Ibíd., p. 229. 
riesgo y la tarea cuando sea necesario para la ejecución del deber tienen el derecho de ser consideradas en este asunto ${ }^{110}$.

En todo caso, y a pesar de su internacionalismo tan contrario a la tradición unilateralista, ésta influyó también en $\mathrm{T}$. Roosevelt como se puede ver en su aversión por las alianzas y su insistencia en formar una sociedad de la paz, pues «las alianzas son muy inestables e inciertas» ${ }^{111}$, pues «las alianzas deben basarse en el interés propio y deben cambiar continuamente ${ }^{112}$, circunstancia que una sociedad como la propuesta por él sortearía, ya que en ella «la prueba sería la conducta y no sólo el interés propio, y así no habría cambios de política»113.

Pero una vez que el Presidente Wilson pidió al Congreso la declaración de guerra a Alemania en abril de 1917, T. Roosevelt apoyaría sin fisuras al Ejecutivo, si bien reaccionó con hostilidad al anuncio de los 14 puntos del Presidente, al negarse a aceptar una organización internacional que desarmase a las potencias e instaurara la libre autodeterminación de todos los pueblos, de hecho, consideraba dicho programa proalemán, y abogó por una unión fuerte con los antiguos aliados, Francia y Gran Bretaña, en las negociaciones de paz, rechazando el papel de mediador que Wilson quería reservar para Estados Unidos ${ }^{114}$

Al respecto, junto a su internacionalismo, a la influencia de la tradición política estadounidense y a su carácter, su nacionalismo también modeló su postura hacia los 14 puntos del Presidente Wilson, pues para T. Roosevelt

«nosotros los nacionalistas contestamos que estamos listos para participar en cualquier sociedad para reforzar la paz o una organización similar que ofrezca la posibilidad de, en alguna medida, rebajar el número y el área de guerras futuras, pero sólo a condición de que en primer lugar no prometamos lo que no vayamos o no debamos realizar, ni seamos culpables de proclamar una mentira, y que en segundo lugar no rindamos nuestro derecho y deber a preparar nuestra propia fuerza para nuestra defensa en lugar de confiar en los pedazos de papel mencionados con anterioridad (acuerdos internacionales no respaldados por la fuerza)»115

110 Ibíd., p. 237. Para T. Roosevelt, fuera del círculo central de las potencias civilizadas se podía incluir a cierto número de naciones para que se pudieran beneficiar de la pertenencia a la Sociedad, pero no formarían parte del primer grupo a no ser que fuesen «civilizadas, se comportasen bien y estuvieran dispuestas a hacer cumplir los decretos del tribunal», p. 239. Así, Estados Unidos, Francia, Gran Bretaña, Alemania, Rusia, Italia, Suiza, Suecia, Holanda, Noruega, Dinamarca, Bélgica, Japón, Brasil, Argentina, Chile y Uruguay sí formarían ese primer grupo, otras naciones como China y Turquía no lo podrían hacer por el momento.

111 ROOSEVELT, T. «Summing Up», America and the World War, Charles Scribner s Sons, New York, 1915, p. 253.

112 Ibíd., p. 254.

113 Ibíd.

114 MORRIS, E. Colonel Roosevelt, op. cit., p. 543 y 547.

115 ROOSEVELT, T. «Sound Nationalism and Sound Internationalism», Roosevelt in the Kansas City Star. War Time Editorials by Theodore Roosevelt, Houghton Mifflin Company, New York, 1921, p. 191. 
Pero sobre todo hay que tener en cuenta que T. Roosevelt, como hemos visto con anterioridad, ya había diseñado su propio plan para asegurar la paz mundial, y por tanto podía enfrentar al diseño del Presidente Wilson sus planes particulares. Así, su realismo le llevaba a advertir, pese a reconocer que ninguna sociedad internacional podría existir sin la presencia de las grandes potencias militares, que ni Alemania, Austria, Turquía ni Rusia podían ser dignas de confianza en tal organización, pues su participación en la misma habría que entenderla como una mera promesa de no recurrir a la guerra, y no a un compromiso firme por preservar la paz mundial ${ }^{116}$, ya que para T. Roosevelt no era tiempo de «colocar nuestra confianza ni en la retórica ni en la hipocresía (...) déjennos ser honestos con nosotros mismos (...) déjennos mirar a la verdad a la cara» ${ }^{117}$, y para el ex Presidente dicha verdad implicaba no confiar en los países que se habían portado mal en el pasado o lo estaban haciendo en el presente, y sobre todo, mantener a Estados Unidos fuerte y preparado para defenderse, pues sólo de esa manera podría defender al mismo tiempo la causa de la paz mundial.

Es más, para T. Roosevelt el único objetivo de Estados Unidos en la guerra era lograr la rendición incondicional de Alemania y sus aliados, todo lo contrario de la paz negociada que suponían los 14 puntos anunciados por Wilson y que tan gustosamente habían aceptado los agresores, pues consideraba que había que repudiar a algunos de ellos y el resto reformularlos en un lenguaje sencillo y franco ${ }^{118}$. Para T. Roosevelt si los 14 puntos implicaban que «Alemania, Austria, Turquía y Rusia, constituidas como en el presente, van a tener influencia en el destino futuro de América, debemos estar en contra de ello» ${ }^{119}$, en su lugar «debemos permanecer junto a nuestros aliados antes que entrar en una Sociedad con nuestros enemigos» 120 .

Sobre la Sociedad de Naciones propuesta por W. Wilson, T. Roosevelt hacía las mismas críticas respecto a los tratados no respaldados por la fuerza, y sólo la apoyaría si suponía un refuerzo, y no un substituto, de la preparación militar nacional, pues

«habrá mucha dificultad en hacerla funcionar cuando llegue un problema serio, y probará ser totalmente inútil si el esfuerzo se hace, en el nombre del internacionalismo, recayendo por entero en ella las tareas, que en el presente estado del mundo, serían efectuadas perfectamente por las naciones libres a condición de que las realicen como deberes nacionales ${ }^{121}$

116 Ibíd., p. 192.

117 Ibíd., p. 194.

118 ROOSEVELT, T. «War Aims and Peace Proposals», Roosevelt in the Kansas City Star. War Time Editorials by Theodore Roosevelt, Houghton Mifflin Company, New York, 1921, p. 226.

119 Ibíd., p. 227.

120 Ibíd. Según T. Roosevelt «lo que no necesitamos es una retórica flexible y hábil que puede ser interpretada para significar cualquier cosa o ninguna», Ibíd., p. 229.

121 ROOSEVELT, T. «Permanent Preparedness and the League of Nations», Roosevelt in the Kansas City Star. War Time Editorials by Theodore Roosevelt, Houghton Mifflin Company, New York, 1921, p. 230. 
De hecho, T. Roosevelt veía contradicciones en los 14 puntos, ya que si por un lado se pedía el desarme, por otro se instauraba el deber de proteger la seguridad de todas las naciones, algo que difícilmente se lograría rebajando el nivel de las respectivas defensas, por ello Roosevelt abogaba para que «el primer paso fuese hacer de la actual alianza con los aliados un interés permanente» ${ }^{122}$. Como hemos visto, T. Roosevelt no creía que los antiguos enemigos pudiesen ser ahora aliados en la nueva sociedad, y por eso, aunque pensaba que Estados Unidos no debía mezclarse en todos los problemas europeos, sí estaba a favor de aunar esfuerzos con Inglaterra, Francia, Italia y «los pequeños Estados que en la práctica se muestren capaces de conducirse ajenos al bolchevismo y al kaiserismo (...) en algún proyecto que en tiempos de gran dificultad ofrezca una posibilidad de obtener acuerdos justos que eviten la guerra» ${ }^{123}$, lo que implicaba limitar la pertenencia a la Sociedad a los aliados de guerra, sin menoscabo de su independencia en ciertos temas de interés vital como las tarifas o la inmigración, y reservar ciertas esferas de influencia a cada nación o grupo de naciones, como Estados Unidos respecto al continente americano manteniendo la vigencia de la Doctrina Monroe, y respecto a los asuntos generales, todas las naciones deberían respaldar las decisiones de algún tribunal creado a tal efecto, incluso con la fuerza si fuese necesario ${ }^{124}$.

La clave de la negativa de T. Roosevelt a la Sociedad de Naciones tal y como la había propuesto el Presidente Wilson radicaba en que «no rendiremos nuestra independencia a ninguna sociedad de naciones como no la rendimos a una sola nación» ${ }^{125}$, ya que «no queremos tomar la responsabilidad de enviar a nuestra galante juventud a morir en oscuras batallas en los Balcanes o en Europa Central, o en una guerra que no aprobamos» ${ }^{126}$.

Cabe destacar que fuera de Estados Unidos y su debate interno sobre la Sociedad de Naciones, también se alzaron voces contrarias a los planes del Presidente Wilson cuyas críticas se correspondían con las realizadas por T. Roosevelt. El Ministro de Asunto Exteriores británico, Arthur Balfour, también estimaba que la duración de la paz dependía por entero de su carácter, pues el sistema internacional de relaciones no debía basarse en fundamentos defectuosos, entre ellos la ausencia de una maquinaria para hacer cumplir las leyes internacionales, de hecho, para Balfour «hay quienes piensan que para esta enfermedad los tratados y

122 ROOSEVELT, T. «Further Considerations of the Fourteen Points», Roosevelt in the Kansas City Star. War Time Editorials by Theodore Roosevelt, Houghton Mifflin Company, New York, 1921, p. 246.

${ }_{123}$ ROOSEVELT, T. «The League of Nations», Roosevelt in the Kansas City Star. War Time Editorials by Theodore Roosevelt, Houghton Mifflin Company, New York, 1921, p. 262-265.

124 Ibíd., p. 263.

125 ROOSEVELT, T. «The League to Enforce Peace», Roosevelt in the Kansas City Star. War Time Editorials by Theodore Roosevelt, Houghton Mifflin Company, New York, 1921, p. 279.

126 ROOSEVELT, T. «The League of Nations», Roosevelt in the Kansas City Star. War Time Editorials by Theodore Roosevelt, Houghton Mifflin Company, New York, 1921, p. 294, del mismo modo que Estados Unidos no debía enredarse en conflictos fuera de su área de influencia, ninguna nación debía inmiscuirse en los asuntos americanos, manteniendo así la vigencia de la Doctrina Monroe. 
las leyes internacionales proveen suficiente cura. Pero estas personas no han comprendido las lecciones tan claramente enseñadas por la historia reciente» ${ }^{127}$. Al igual que T. Roosevelt, Balfour no creía en una paz sin vencedores, sino que para que no se repitiesen los terribles acontecimientos que había presenciado Europa, estimaba que al menos se debían cumplir las siguientes condiciones, primero, eliminación de las causas del malestar internacional, segundo, repulsa de los métodos de los Estados agresores por sus propias poblaciones y por último, «que detrás de la ley internacional, y detrás de todos los tratados para prevenir y limitar las hostilidades, se diseñe alguna forma de sanción internacional que frene incluso al más duro de los agresores ${ }^{128}$. En esencia, a lo que Balfour se oponía era a conceder a los agresores el mismo trato que a los aliados, y permitirles decidir sobre el futuro mundial como si nada hubiese pasado en los últimos años, pues para el ministro británico «del éxito de los aliados dependen las posibilidades de una civilización pacífica y de las reformas internacionales que los mejores pensadores del Nuevo mundo, y del Viejo, esperan se den tras el cese de las presentes calamidades»129. No en vano, Balfour había anunciado en 1910 la propuesta de «La posibilidad de una Federación Anglosajona» ${ }^{130}$, usando su superioridad naval para mantener el equilibrio mundial, en consonancia con el deseo de T. Roosevelt de que Estados Unidos sustituyera a Gran Bretaña como árbitro mundial.

En síntesis, las principales objeciones de T. Roosevelt al programa de los 14 puntos y a la Sociedad de Naciones del Presidente Wilson se pueden resumir en:

1. Falta de claridad en los principios y puntos esgrimidos, pues para unos podían significar una cosa y para otros la contraria, impidiendo así que la paz llegue a ser permanente,

2. Ir en contra de la preparación nacional, ya que al pedir el desarme de las naciones, Wilson amenazaba con dejar a Estados Unidos indefenso ante futuras agresiones, y a la Sociedad de Naciones incapaz de hacer frente a sus propias funciones, ya que sin la fuerza de sus miembros, la Sociedad por sí misma no podría ayudar a nadie,

3. Favorecer a los agresores, pues en lugar de imponer la paz a los mismos, el Presidente Wilson trataba de imponer sus puntos a todos por igual, sin distinciones, en una paz negociada que no acabaría con las causas que habían conducido a la guerra, y que iba en contra de la voluntad del pueblo estadounidense,

4. Incluir a todas las naciones, ya que en opinión de T. Roosevelt sólo aquellas potencias dispuestas y capaces de defender los principios y decisiones de

127 BALFOUR, Arthur «The Foundations of a Durable Peace», Essays Speculative and Political, George H. Doran Company, New York, 1921, p. 226.

128 Ibíd., p. 229.

129 Ibíd., p. 230.

130 MORRIS, E. Colonel Roosevelt, op. cit., p. 71. 
la nueva Sociedad eran dignas de pertenecer al núcleo central de la misma, el resto, o bien sólo en calidad de beneficiarias o, como en el caso de los agresores que no se reformasen, estarían fuera de ella,

5. Socavar la independencia y soberanía estadounidenses al proclamar principios como la libertad de mares o la liberalización del comercio mundial, pues la pertenencia a la Sociedad no debía ser obstáculo, según T. Roosevelt, para que Estados Unidos conservase determinadas esferas de interés reservadas a su propia voluntad.

6. No incorporar un mecanismo claro para hacer cumplir las decisiones de la Sociedad, sin él, para T. Roosevelt ésta no sería más que otro pedazo de papel que se podría romper a voluntad de las potencias, como había pasado hasta entonces con los anteriores tratados internacionales.

Conociendo la postura de T. Roosevelt sobre la Sociedad de Naciones, cabe preguntarse cual hubiese sido su postura en el debate entre la Administración Wilson y el Senado, iniciado tras su muerte el 6 de enero de 1919.

Si bien es cierto que en 1916 había apoyado a regañadientes al candidato Republicano C. E. Hughes con tal de no ver a Wilson renovar su mandato ${ }^{131}$, y había visto la victoria Republicana en la elecciones de medio término de noviembre de 1918 como una derrota de los planes del Presidente Wilson y una victoria del americanismo ${ }^{132}$, lo cierto es que nada seguro se podía esperar del carácter de T. Roosevelt.

Respecto al Internacionalismo conservador del Partido Republicano, cabe afirmar que para $\mathrm{T}$. Roosevelt la mayoría de las enmiendas presentadas por éste en el Senado para cambiar el plan del Presidente Wilson eran de su agrado, incluso apoyaba el esquema presentado por Taft en una Sociedad para imponer la Paz, pues no entraba en contradicción con la preparación militar nacional, aceptaba la necesidad de reconocer las esferas de influencia para cada potencia y el respeto de la Doctrina Monroe, además de salvaguardar los intereses nacionales ante la injerencia de tribunales internacionales ${ }^{133}$.

Pero tales coincidencias no hubiesen sido obstáculo para una nueva ruptura con el Republicanismo, pues existía una diferencia vital entre el Internacionalismo Republicano y el de su antiguo líder, a saber, mientras aquel se contentaba con firmar pactos internacionales con tal de no ver implicada con ello la soberanía nacional y comprometido el juego de equilibrio y balance de poderes Estatales sancionado en su constitución, bien al contrario, T. Roosevelt defendía que la ley

131 Ibíd., p. 467.

132 ROOSEVELT, T. «An American Congress», Roosevelt in the Kansas City Star. War Time Editorials by Theodore Roosevelt, Houghton Mifflin Company, New York, 1921, p. 266.

133 ROOSEVELT, T. «The League to Enforce Peace», Roosevelt in the Kansas City Star. War Time Editorials by Theodore Roosevelt, Houghton Mifflin Company, New York, 1921, p. 278-280. 
internacional fuese de obligado cumplimiento, incluso bajo la amenaza del uso de la fuerza por parte de las potencias mundiales dispuestas a ello.

Si ya con anterioridad su excepcionalismo enérgico había sido sustituido por la diplomacia del dólar de su sucesor, la insistencia de T. Roosevelt en un mecanismo capaz de implicar a las grandes naciones en el uso de la fuerza para garantizar la paz mundial hubiese tenido el mismo destino, pues el Republicanismo regular, representado por sus cercanos Root y Lodge, lo último que tenía en mente era ir más allá de lo estipulado por el Presidente Wilson, dado que su objetivo era limitar sus propuestas para que la soberanía nacional no se viese socavada por ninguna organización internacional y así mantener a Estados Unidos lejos de conflictos que no afectasen a sus intereses vitales. Aunque T. Roosevelt también se oponía a comprometer las tropas estadounidenses en cualquier conflicto, lo cierto es que su predisposición a usarlas por el bien de la civilización iba mucho más allá de lo que el Republicano medio estaba dispuesto a aceptar, por el contrario, el Internacionalismo sin compromiso que se impuso en el periodo de entreguerras ilustra a la perfección la postura Republicana al respecto, con el Tratado Briand-Kellog de 1928 como mejor ejemplo de ello, un pacto que T. Roosevelt hubiese rechazado por representar el tipo de tratados no respaldados por ningún régimen sancionador y que se convertían en papel mojado ante la impunidad de cualquier acto agresivo.

Por tanto, la lealtad de T. Roosevelt al Partido Republicano durante el debate por la Sociedad de Naciones no es algo que se pudiera dar por seguro, en última instancia se hubiese amoldado al sentir mayoritario del Partido, pero sólo para impedir que los planes del Presidente Wilson fuesen aprobados. Sus diferencias respecto al Internacionalismo Republicano seguían siendo muy profundas, y su insistencia en un mecanismo sancionador demasiado adelantada a su tiempo y contraria al deseo general del pueblo estadounidense por alejarse de lo que se consideraban problemas ajenos al interés nacional. Sin duda que T. Roosevelt no se hubiese sentido muy a gusto en su propio país, ni de acuerdo con su Partido Republicano, durante los felices años 20, con unos Estados Unidos volcados en el aumento y disfrute desmedido de su riqueza, mientras daban la espalda a los conflictos que se gestaban en Europa y que de nuevo afectarían a América.

\section{CONCLUSIONES}

Por lo tanto, una vez estudiado el Internacionalismo conservador bajo su presidencia, así como el debate por la Sociedad de Naciones y las diferencias entre el Internacionalismo Republicano y el de T. Roosevelt, es el momento de finalizar el presente trabajo con las siguientes conclusiones:

* La presidencia de T. Roosevelt tuvo un impacto enorme en Estados Unidos, y en particular en su política exterior, pues con una base ideológica discernible, un firme internacionalismo y una evidente plasmación práctica de todo 
ello, el Internacionalismo conservador del Presidente T. Roosevelt y su equipo se dotó de las dimensiones necesarias para convertir su programa en el primer ensayo internacionalista en la historia de la política estadounidense. Con una mezcla de realismo hamiltoniano aderezado con la importancia concedida a los aspectos económico-comerciales de la política exterior nacional y de un populismo jacksoniano salpicado en ocasiones por un nacionalismo y una política de fuerza poco sofisticados, la Administración de T. Roosevelt supo apartar a la diplomacia estadounidense de sus comienzos aislacionistas ${ }^{134}$ y dotarla así de un nuevo carácter intervencionista en los asuntos mundiales. El internacionalismo conservador fue el primer intento de reorientación estratégica emprendido en Estados Unidos, ya que hasta el momento, los líderes de la nación se habían contentado con finalizar la conquista continental y curar las heridas de la Guerra Civil, pero con la adquisición del imperio de ultramar y la voluntad de una nueva generación de políticos, Estados Unidos adquirió un nuevo status de potencia mundial que la alejaba definitivamente de los sueños jeffersonianos de una pequeña república cuya revolución había triunfado, muy al contrario, surgía así un gigante en plena expansión con el firme propósito de continuar con la misión de propagar su modelo allá donde se encaminase. A partir de entonces, quisieran o no, sus sucesores debieron de hacer frente a los nuevos retos derivados de la recién adquirida condición de potencia mundial de Estados Unidos, ya que con T. Roosevelt la joven república adquirió unos compromisos desconocidos hasta entonces que la alejaban de su plácido pasado de unilateralismo aislacionista. Además, al basar su Internacionalismo conservador en el realismo continental europeo, T. Roosevelt introdujo en el debate interno estadounidense un vector, que si bien hasta el momento había estado presente de forma latente, a partir de entonces entraría a formar parte del propio acervo político de Estados Unidos, así, futuros Presidentes como F. D. Roosevelt o R. M. Nixon se valdrían del realismo para poner en práctica sus políticas exteriores. De ahí que dos figuras clave del internacionalismo estadounidense como fueron T. Roosevelt y W. Wilson aparezcan generalmente enfrentadas como representantes de dos concepciones opuestas sobre la política exterior estadounidense, cuando en realidad la dicotomía se basa más bien en el enfoque realista que introdujo T. Roosevelt en su presidencia, en contraposición al idealista utilizado por W. Wilson, quien convirtió los principios y valores encarnados en la Constitución estadounidense en el sustento de su internacionalismo, cuando hasta el momento habían servido de principal justificación del unilateralismo aislacionista.

* Si con el nacimiento de Estados Unidos su clase política ya había dado sobradas muestras de su hondo calado intelectual, pues desde la Declaración

134 Si bien aquí cabría recordar que siguiendo a McDougall el aislacionismo norteamericano se entiende como una muestra de su unilateralismo. 
de Independencia en 1776 hasta la aprobación de la Constitución en 1788, transcurre uno de los periodos de mayor riqueza en cuanto a pensamiento constitucional se refiere, con The Federalist Papers como máximo exponente; con el debate sobre la Sociedad de Naciones ocurre algo similar respecto a asuntos de paz y seguridad internacional, pues al calor de los debates internos, el Senado estadounidense ofreció al mundo toda una serie de argumentos a favor y en contra de una unión internacional que todavía hoy continúan resonando con total vigencia, en particular, dos décadas más tarde, las reservas presentadas por el Partido Republicano fueron tenidas en cuenta por F. D. Roosevelt en la creación de las Naciones Unidas, consciente de que el único modo de evitar un nuevo rechazo a la entrada de Estados Unidos en una organización internacional, era integrar en su plan las principales restricciones del internacionalismo conservador, sobre todo en lo relativo a los poderes del Congreso en materia de política exterior y en todo aquello que limitase la libertad de acción estadounidense, de hecho, aun hoy Estados Unidos continúa siendo muy celoso al respecto, como atestiguan los numerosos tratados bilaterales firmados con terceros países para proteger al personal estadounidense, civil y militar, destinado en misiones internacionales, a la vez que toda intervención de Estados Unidos en misiones militares de la ONU, sigue despertando las mismas reticencias que en la década de 1920 lo hacía la entrada en la Sociedad de Naciones, usándose prácticamente los mismos argumentos hoy que entonces.

* Misma vigencia cabe reclamar para el pensamiento político de T. Roosevelt, figura que como se ha tratado de demostrar en el presente trabajo, iba mucho más allá del rudo jingoísta estadounidense a la que en muchas ocasiones se le reduce. A pesar de que la Sociedad de Naciones fue sustituida por la Organización de las Naciones Unidas tras la II Guerra Mundial, con el final de la Guerra Fría el mundo sigue acuciado por los mismos problemas que se tuvieron que encarar tras la I Guerra Mundial, y que como tan bien supo apreciar T. Roosevelt, se pueden resumir en la falta de un mecanismo sancionador que haga cumplir la ley internacional. Hoy, como hace casi un siglo, son esas potencias a las que T. Roosevelt apelaba, las mismas que siguen sin aunar sus esfuerzos por la causa de la paz internacional, quizá por falta de voluntad, quizá por la inexistencia de una visión compartida sobre cómo debería ser el mundo, pero lo cierto es que las mismas quejas que T. Roosevelt realizó al programa del Presidente Wilson, se pueden hacer hoy al actual orden mundial, pues como el propio T. Roosevelt se lamentaba acerca de los tratados de arbitrio

«ha sido un infortunio que algunas personas dignas se hayan anticipado y proclamado demasiado en referencia a ellos (tratados internacionales), pues el fracaso de las excesivas reclamaciones ha cegado a los hombres respecto a lo que verdaderamente han logrado. Esperar de ellos lo que no pueden dar es imprudente. Asegurar que pueden ofrecer lo que no pueden dar es malicioso. Prometer lo que 
no pueden ofrecer no es sólo malicioso sino hipócrita; y esa es la razón por la que esos tratados (...) son imperceptiblemente dañinos ${ }^{135}$

* En el Internacionalismo conservador de T. Roosevelt se puede apreciar cierto endurecimiento en su creencia sobre las posibilidades de una organización internacional efectiva. En efecto, su pensamiento evolucionó desde un nacionalismo enérgico en su etapa en la Casa Blanca, que tan sólo concedía a la colaboración interestatal los acuerdos mediante la figura del arbitrio internacional, método de resolución pacífica de las controversias impulsado por E. Root y que las convenciones de La Haya trataron de institucionalizar. Pero una vez fuera de la presidencia, el desencanto de T. Roosevelt con tales arreglos fue creciendo a medida que la situación internacional empeoraba, sin que los tratados pudieran evitarlo. En consecuencia, T. Roosevelt fue virando hacia un internacionalismo que defendía poner la fuerza militar estadounidense al servicio de la paz mundial, sin menoscabo de la soberanía nacional y siempre que fuera en pie de igualdad con el resto de potencias, unidas en una empresa colectiva común. Sin duda que la radicalización del pensamiento de $\mathrm{T}$. Roosevelt tuviera mucho que ver con su alejamiento de los centros de toma de decisiones, máxime si tenemos en cuenta que durante su etapa como Presidente de Estados Unidos, su excepcionalismo enérgico se vio atemperado por el componente realista de su Internacionalismo, y es que es una constante en la vida política democrática que los discursos sean mucho más viscerales y extremistas fuera del poder, como en el Senado por ejemplo, y que se templen una vez alcanzado el mismo, como el ejemplo de T. Roosevelt demuestra a la perfección.

* Como se ha visto a la hora de analizar la política exterior de la Administración de T. Roosevelt, sus acciones tanto en Europa como en Asia trataban de mantener el equilibrio de poder entre franceses y alemanes por un lado, y entre rusos y japoneses por otro, es decir, que en gran parte, al reconocer que en el interés nacional de Estados Unidos se debía intervenir para que ninguna potencia se hiciese con el control de ciertas regiones estratégicas, $\mathrm{T}$. Roosevelt estaba adaptando para Estados Unidos la clásica política exterior británica de balance de poder aplicada durante todo el siglo XIX en Europa con Castlereagh, Palmerston, Gladstone o Canning ${ }^{136}$, consecuencia, que por otra parte, resultaba totalmente lógica con la creencia de T. Roosevelt de que Estados Unidos debía sustituir a Gran Bretaña como árbitro del concierto mundial. Tal adaptación culminaba un proceso de paulatino acercamiento entre la ex metrópoli y su antigua colonia, y que en 1901 había conducido al Tratado Hay-Pauncefote por el cual Londres reconocía la primacía de Washington en la construcción del Canal interoceánico en Panamá137, y dos

135 ROOSEVELT, T. America and the World War, op. cit., p. 58.

136 KISSINGER, Henry Diplomacia, Ediciones B, Barcelona, 2000. p. 117, 130 y 202.

${ }_{137}$ LEECH, Margaret In the Days of McKinley, Harper \& Brothers, New York, 1959, p. 506 y 514. 
años más tarde, al Tratado Hay-Herbert por el que se trazaba la frontera definitiva entre Canadá y Estados Unidos ${ }^{138}$, sellando así la solidaridad anglosajona que perdura hasta nuestros días, además, no hay que olvidar que había sido el Servicio Imperial Marino de Aduanas británico quien sugirió a J. Hay la promulgación de su famosa política de puertas abiertas para China, cuando los intereses de Estados Unidos y Gran Bretaña coincidían plenamente en la región ${ }^{139}$, y ya hemos visto cómo las reservas de A. Balfour a la Sociedad de Naciones propuesta por W. Wilson, coincidían a grandes rasgos con las formuladas por T. Roosevelt. Por tanto, el Internacionalismo conservador de $\mathrm{T}$. Roosevelt debe mucho a su conocimiento y admiración de la política exterior británica y a su intento por adaptarla a la acción exterior estadounidense, bajo el prisma de un realismo extraño hasta entonces en el acervo político estadounidense.

* En sus críticas a la Sociedad de Naciones, y como alternativa a la misma, T. Roosevelt avanzó en gran medida lo que serían las notas definitorias de la Alianza Atlántica, que nació como respuesta europea y de la Administración Truman a la ineficacia de las Naciones Unidas. Como hemos visto, T. Roosevelt estaba en contra de que países que no compartieran las mismas reglas de comportamiento formasen parte de la misma organización, ni qué decir tiene de los órganos ejecutivos de la misma, como sí sucedía en la Sociedad de Naciones y de hecho sucede en la ONU, pero no en la OTAN, y como el propio T. Roosevelt defendía, se debía limitar la participación en la organización a los aliados de la I Guerra Mundial, dejando para el futuro la eventual incorporación del resto de naciones, a condición de su reforma interna. Pero lo que distingue a la OTAN de la ONU, más allá de su carácter regional, es la existencia de un sistema efectivo de defensa solidario, con unas reglas bien definidas y claras, todo cuanto $T$. Roosevelt reclamaba para una organización internacional que de verdad quisiera hacer de la paz una realidad permanente, algo no sólo compatible, sino imprescindiblemente necesario junto a la preparación militar de cada nación, pilar básico, y fuente constante de fricciones, de la Alianza Atlántica, y que como se ha comprobado, era una de las principales preocupaciones de T. Roosevelt, pues su realismo le llevaba a no engañarse al respecto, plenamente consciente de que el éxito de las organizaciones internacionales depende, en última instancia, no tanto de la letra de sus acuerdos, como de la voluntad de sus miembros por respetarlos y cumplirlos. En efecto, la Sociedad de Naciones al no contar con un sistema de defensa colectivo como se encuentra en el art. 5 del Tratado de la Alianza Atlántica, y un art. 3 de solidaridad en el mantenimiento de las capacidades para resistir ataques armados ${ }^{140}$, no podría

138 ZIMMERMANN, Warren First great triumph, how five americans made their country a World power, FSG Books, 2002, p. 452.

139 KENNAN, George F. American Diplomacy 1900-1950, Mentor Books, New York, 1952, p 26-30.

140 Tratado de la Organización del Atlántico Norte, texto consultado en http://www.nato.int/cps/en/natolive/official texts 17120.htm 
hacer frente al tipo de conflictos que condujeron a la II Guerra Mundial, de igual modo que las Naciones Unidas siguen sin contar con un sistema de seguridad coercitivo, y menos aun con unas fuerzas militares propias que subsanen la falta de voluntad de sus miembros. De ahí que la OTAN, en especial con sus art. 3 y 5, tratase de vencer las limitaciones de la organización internacional, a través de una unión regional que, esta vez sí, recogiendo en gran medida las ideas de T. Roosevelt, lograse un sistema de defensa colectivo efectivo ${ }^{141}$.

En suma, y como se ha podido apreciar, el pensamiento político de T. Roosevelt no sólo nos ayuda a comprender una etapa trascendental en la historia estadounidense y mundial, sino que gracias a su profundidad resulta de una pertinencia innegable, pues al ser el primer Presidente en tratar de alejar a Estados Unidos de su tradicional unilateralismo aislacionista en materia de política exterior, y encaminarlo hacia el internacionalismo, comenzó un debate que aun en nuestros días no se ha despejado del todo, ni a nivel estadounidense, ni a nivel mundial, ya se trate de la propia política exterior del gigante americano, ya sea sobre el alcance e implicaciones de la colaboración internacional para el mantenimiento de la paz mundial.

${ }^{141}$ Cabe señalar al respecto, que el último gran debate por la aprobación de la OTAN en el Congreso de Estados Unidos no se dio con su nacimiento, pese a la ardua tarea que supuso la elaboración de un art. 5 capaz de sortear las reticencias de los sectores menos internacionalistas, sino con la implementación del art. 3 y el refuerzo del contingente estadounidense destinado en Europa. En él, R. Taft lideró la oposición al envío de más divisiones a Europa, en lo que se convirtió en la última ocasión en que el unilateralismo aislacionista trató de menoscabar la dominante influencia internacionalista en la política exterior de Estados Unidos. 
